\title{
Chapter 10: Solar thermoelectric technologies for power generation
}

Guiqiang Li

School of Engineering and Computer Science

University of Hull, UK

Email: Guiqiang.LI@hull.ac.uk

Xiaoli Ma

School of Engineering and Computer Science

University of Hull, UK

Email: x.ma@hull.ac.uk

Samson Shittu

School of Engineering and Computer Science

University of Hull, UK

Email: S.Shittu@2016.hull.ac.uk

Abstract: Thermoelectric power generation (TEG) is the most effective process that can create electrical current from a thermal gradient directly, based on the Seebeck effect. Solar energy as renewable energy can provide the thermal energy to produce the temperature difference between the hot and cold sides of the thermoelectric device. This chapter introduces various solar thermoelectric technologies including micro-channel heat pipe evacuated tube solar collector incorporated thermoelectric power generation system, solar concentrating thermoelectric generator using the micro-channel heat pipe array, and novel photovoltaicthermoelectric power generation system. The details of these systems are illustrated, and their performance is analyzed. This chapter would provide a valuable reference for the study and applications of the solar thermoelectric power generation technologies.

Keywords: TEG, Solar energy, Micro-channel heat pipe, Solar thermoelectric, PV-TE

\subsection{Introduction}

Extensive fossil fuel consumption by human activities has led to serious atmospheric and environmental problems. Consequently, global warming, greenhouse gas emission, climate change, ozone layer depletion and acid rain terminologies have started to appear frequently in the literature. To abate the impact of the above disasters, the thermoelectric (TE) energy 
converter is proposed as one of the possible technologies for this aim, and it as currently gained the most popularity owing to its capability to convert the heat given off from vehicles, electrical instruments, etc. into electricity. The merits of this conversion lie in the solid-state operation, the gas-free emissions, the vast scalability, the maintenance-free operation without any moving parts and chemical reactions, no damage to the environment and a long life-span of reliable operation.

Solar energy, known as a free, reliable, and inexhaustible source of clean energy, is regarded as one of the most promising solutions to reduce the consumption of fossil fuels and improve environmental issues. Solar thermoelectric generators (STGs or STEGs) have been the research focus of thermoelectric technology in recent years.

\subsection{Thermoelectric generation technologies}

The TE phenomenon was discovered in the 18th century, it generated a rather small voltage between two dissimilar metals, and it was mostly used as thermocouples. With the invention of high-efficient semiconductor, the TE technology has experienced a rapid development over the last 60 years owing to its unique characteristics differentiating it from traditional energy generator.

Seebeck effect was found in 1821 and it disclosed that two joint dissimilar metals have the different temperatures $(\Delta T)$ at the joints, and the corresponding current and electromotive force existing in the joint circuit are called the thermo-current and thermo-electromotive force respectively. Increasing the voltage difference $(\Delta V)$ enlarges the temperature difference between two joints $(\Delta T)$. The proportional constant related to the intrinsic property of the material is known as the Seebeck coefficient. This coefficient is relatively low for materials like metals at approximately $0 \mu \mathrm{V} / \mathrm{K}$, while it would be much larger at around $\pm 200 \mu \mathrm{V} / \mathrm{K}$ for the semiconductor.

$\alpha=\Delta V / \Delta T$

As a result, a thermoelectric generator (TEG) can be used for power generation when its two 
materials are exposed to different temperatures, as shown in Figure 10.1.

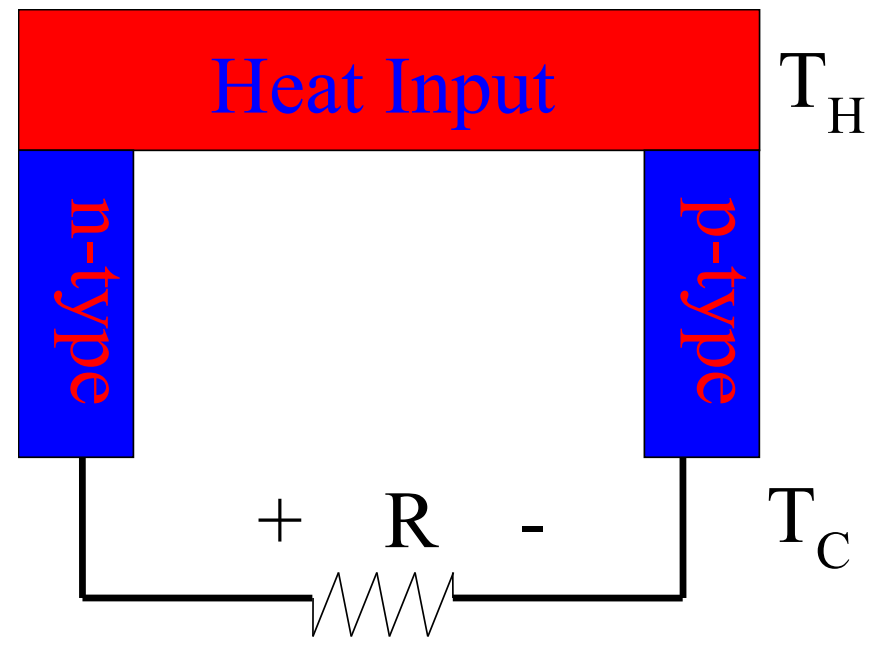

Figure 10.1 The schematic diagram of thermoelectric generator

The TEG efficiency can be estimated by:

$\eta_{\max }=\frac{T_{H}-T_{C}}{T_{H}} \cdot \frac{\sqrt{1+Z T}-1}{\sqrt{1+Z T}+\frac{T_{C}}{T_{H}}}$

Where $\mathrm{T}_{\mathrm{C}}$ is the cold side temperature, $\mathrm{T}_{\mathrm{H}}$ is the hot side temperature.

According to Eq. (10.2), when the ZT is infinite, the efficiency is the Carnot. Therefore, there is a theory that claims that thermoelectric generators are Carnot hot engines, where electrons perform as the working medium.

$Z T=\frac{\alpha^{2}}{\kappa} \sigma T$

Where $\alpha$ is the Seebeck coefficient, $\sigma$ is electrical conductivity, $\kappa$ is thermal and $\mathrm{T}$ is temperature.

The efficiency is governed by the dimensionless parameter, figure of merit ZT which is defined as Eq. (10.3). This formula is associated with three physical properties intrinsic to the material: the electrical resistivity $\sigma$, the thermopower or Seebeck coefficient $\alpha$, and the thermal conductivity $\kappa$, all given at the absolute temperature T. The conventional strategy to enhance the ZT values consists in modifying the crystalline structure of materials that possess inherently good electrical properties by alloying and/or inserting foreign species to decrease the thermal conductivity. Alternatively, designing novel materials with the inherently low thermal 
conductivity values would leave the power factor $\frac{\alpha^{2}}{\sigma}$ the only relevant parameter to be optimized. On fabricating TE modules, both p- and n-type TE materials are required.

Since the late 1950s, the semiconductor thermoelectric devices have been applied for terrestrial power generation and later for space power generation due to their competitive energy conversion compared to other types of small-scale electric power generators. The semiconductor thermoelectric power generation, based on the Seebeck effect, has very interesting capabilities with respect to conventional power-generation systems.

During the1990s, there was a heightened interest in the field of thermoelectric which was largely driven by the need for more efficient materials for power generation. For better use of semiconductor materials for thermoelectric applications, considerable efforts have been made to improve the figure of merit $(\mathrm{ZT})$ value of these materials to greater than 3 to make them commercially viable.

\subsection{Application of the solar thermoelectric technologies}

\subsubsection{Micro-channel heat pipe evacuated tube solar collector incorporated thermoelectric (MHPETC-TEG)}

\section{A) MHPETC-TEG introduction}

The evacuated heat pipe incorporated with a thermoelectric module is shown in Figure 10.2. The integrated solar heat pipe thermoelectric generator module consists of a square channel for the cooling water, a thermoelectric generator, a heat pipe with selective absorbing coating and an evacuated tube. 


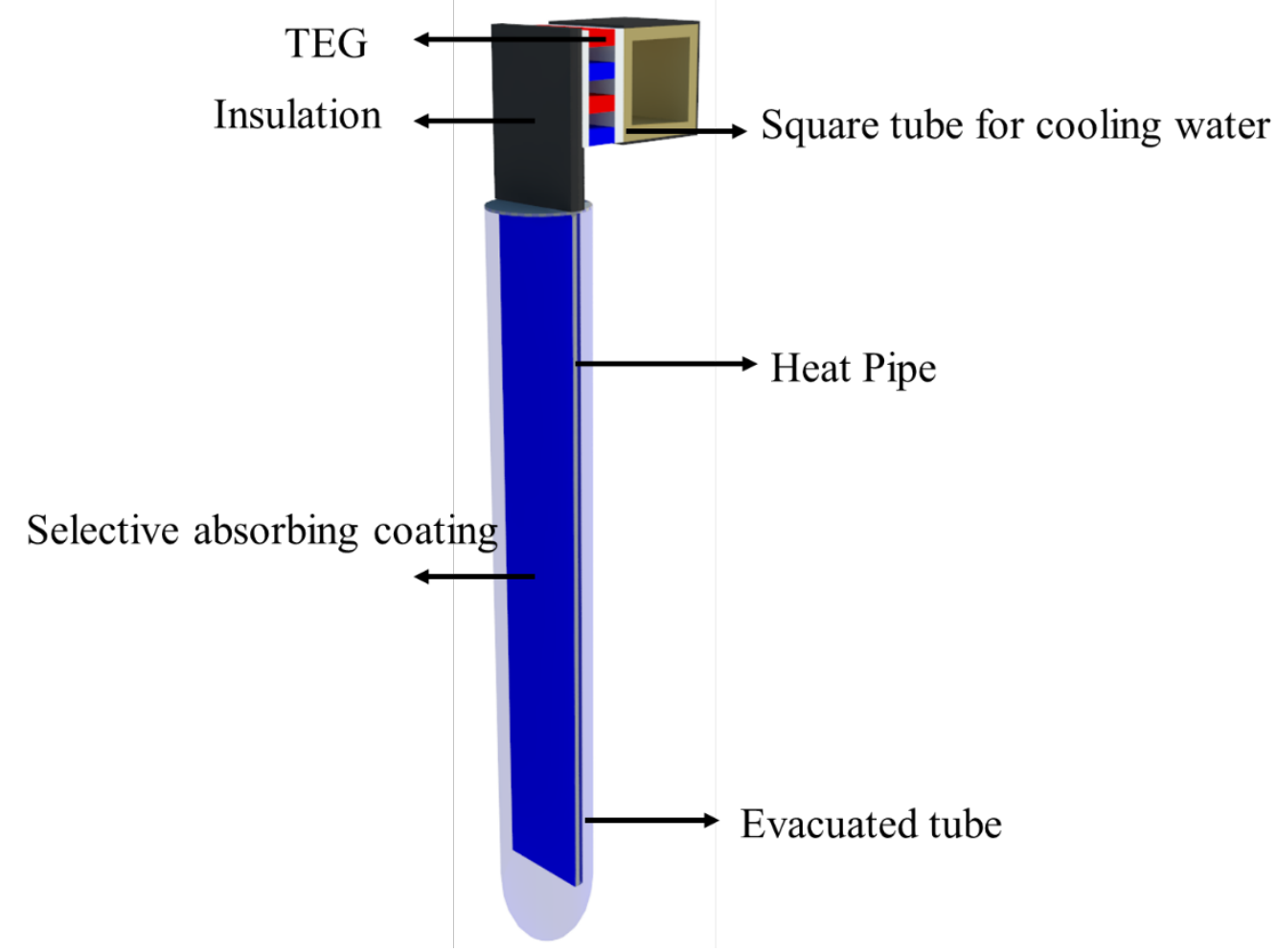

Figure 10.2 Schematic diagram of the micro-channel heat pipe evacuated tube solar collector incorporated thermoelectric module

The design concept of the micro-channel heat pipe evacuated tube solar collector incorporated into a thermoelectric generator which is installed on the wall is shown in Figure 10.3. For a micro-channel heat pipe evacuated tube solar collector incorporating a thermoelectric module, the thermal energy collected by the heat pipes is transferred to the TEG, then the cooling water in the square tube which is attached to the hot side surface of the TEG takes the heat away. For the MHPETC-TEG system, the modules are connected in series. 


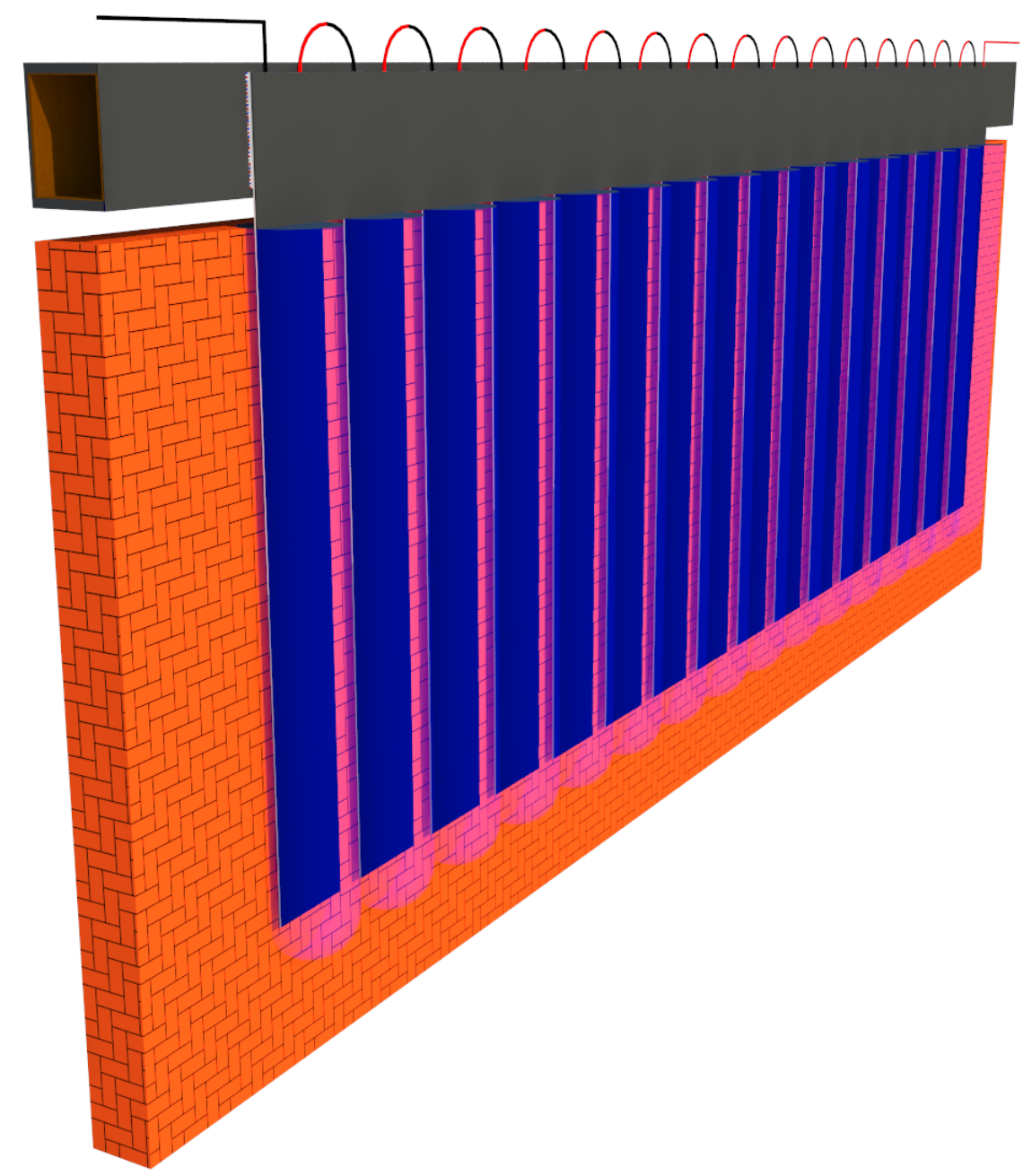

Figure 10.3 The installation diagram of the MHPETC-TEG system

In China, due to the emergence of a large number of high-rise buildings, the solar hot water heater system often uses the balcony wall-mounted method for installation. Thus, in the design the heat pipe evacuated tube solar collector is on the outside of the wall. The array of the evacuated heat pipe incorporated with thermoelectric generators is in series connection. The heat eventually conducted through TEGs is carried away by water and thus, causes the temperature increase of the cooling water and the electricity generation by TEG.

\section{B) MHPETC-TEG Performance Analysis}

\section{a) Different solar radiations}

When the input water temperature is $25^{\circ} \mathrm{C}$ and the hot water flow rate is $0.06 \mathrm{~m} / \mathrm{s}$, the output water temperature and the selective absorbing coating temperature under different solar radiations are shown in Figure 10.4. It is clear that high solar radiation responds to high output 
water temperature and the selective absorbing coating temperature. Furthermore, increase in number of MHPETC-TEG modules would lead to an increase in the output water temperature (Figure 10.4a). In addition, the selective absorbing coating temperature is significantly higher than the ambient temperature, even when the solar radiation is $100 \mathrm{~W}$, the selective absorbing coating temperature is about $12^{\circ} \mathrm{C}$ higher than the ambient temperature (Figure 10.4b).

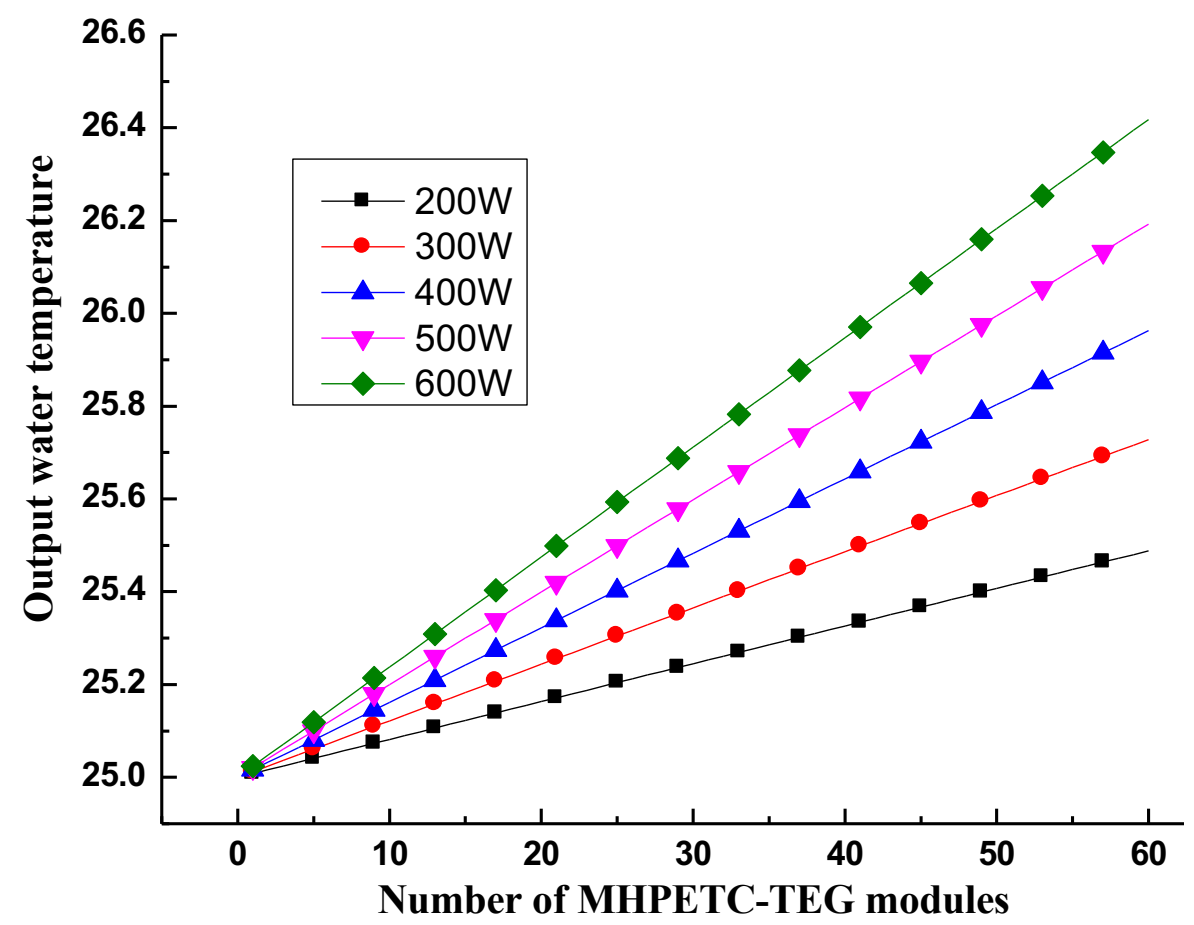

(a) 


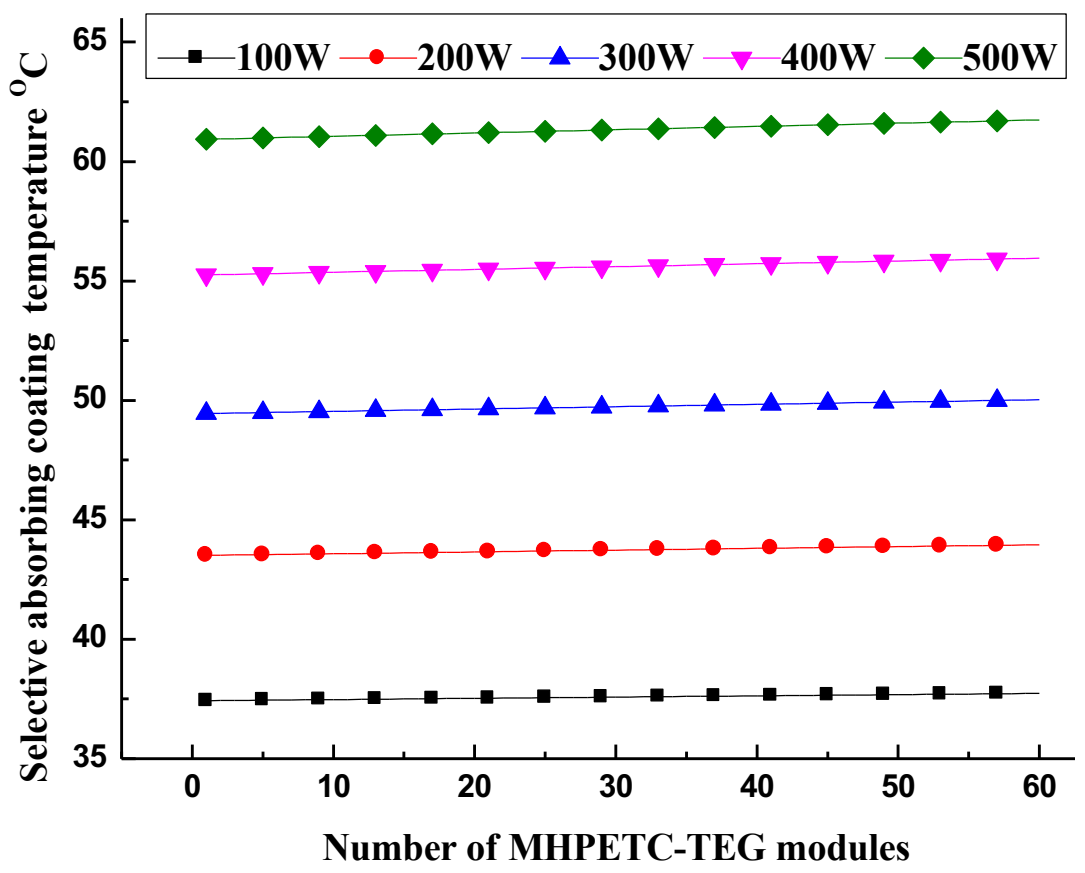

(b)

Figure 10.4 Temperature variation $\left(T_{\text {in }}=25^{\circ} \mathrm{C}, u_{f}=0.06 \mathrm{~m} / \mathrm{s}\right)$

With the increase of the number of the MHPETC-TE modules, the thermal efficiency has a decreasing tendency (Figure 10.5a), and that of the electrical efficiency has a relatively stable value (Figure 10.5b). In addition, when the solar radiation is $200 \mathrm{~W}$, the thermal efficiency has a higher value, but the electrical efficiency has a lower one. This is because when the solar radiation is low, the selective absorbing temperature has a low value, thus the radiation heat loss is less, but the hot side temperature of the TEG module is low which leads to a less temperature difference and a less electrical output. 


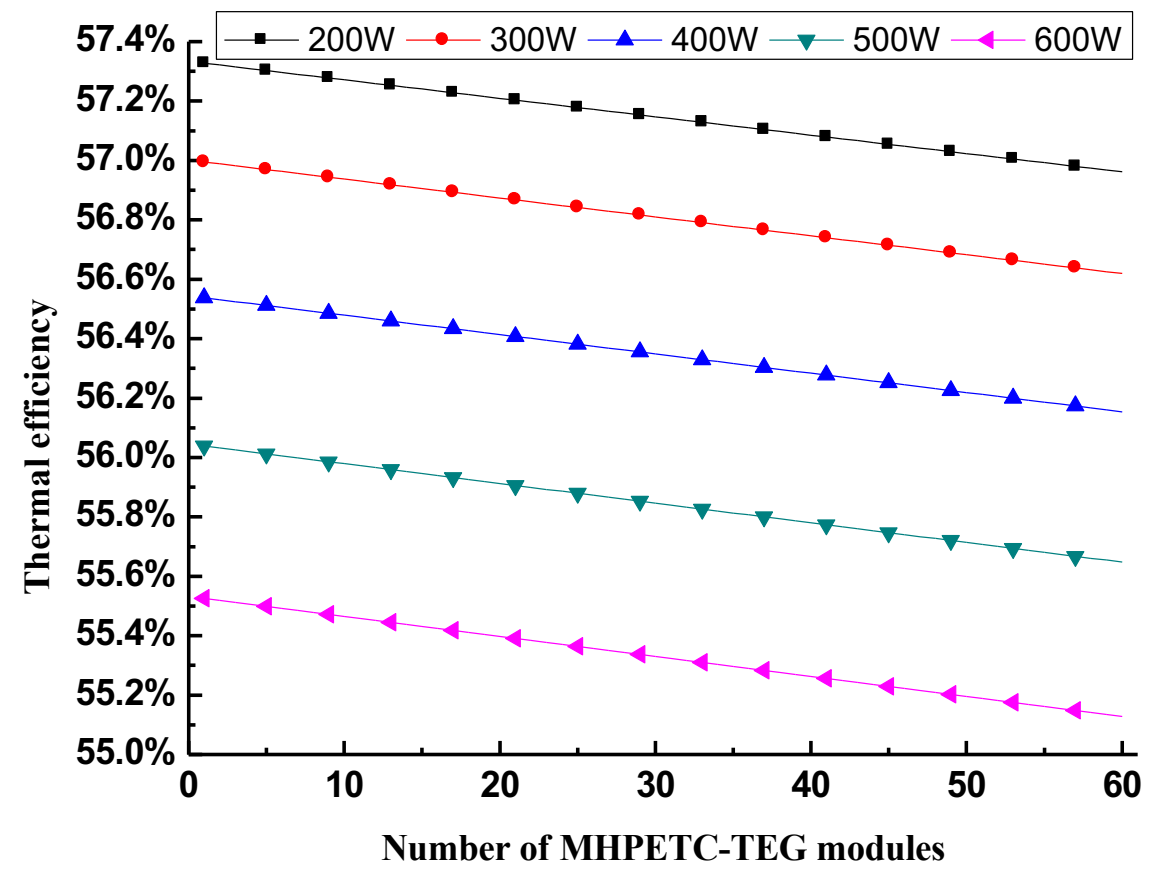

(a)

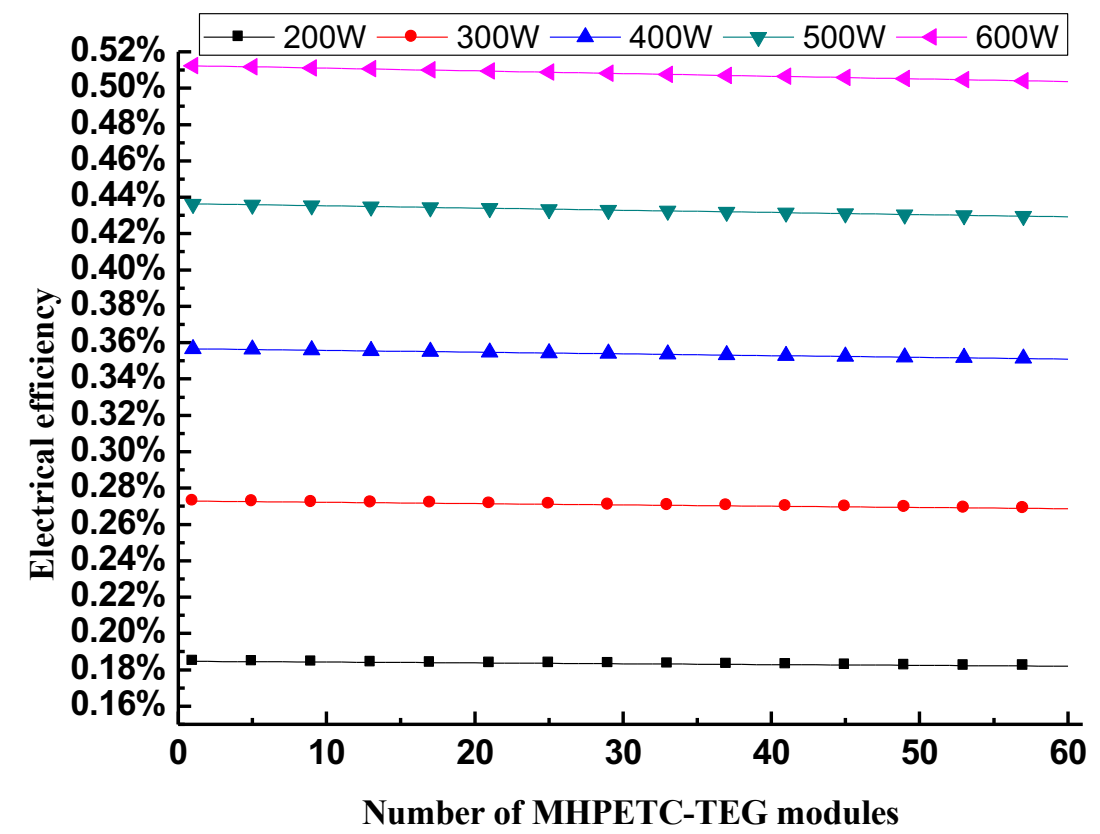

(b)

Figure 10.5 Thermal and electrical efficiency $\left(T_{i n}=25^{\circ} C, u_{f}=0.06 m / s\right)$

It is clear that with the increase in the number of the MHPETC-TE modules, the exergy efficiency of the hot water has an increasing tendency (Figure 10.6a) which is different from the tendency of the thermal efficiency. However, for the exergy of TEG, the tendency of the exergy efficiency with the increase in the number of the MHPETC-TE modules is as the same 
as that of the electrical efficiency of TEG (Figure 10.6b). In addition, under the higher solar radiation, the exergy efficiency of the hot water and the TEG all have a larger value since the output water temperature has a higher value and TEG has a larger temperature difference between the hot and cold sides.

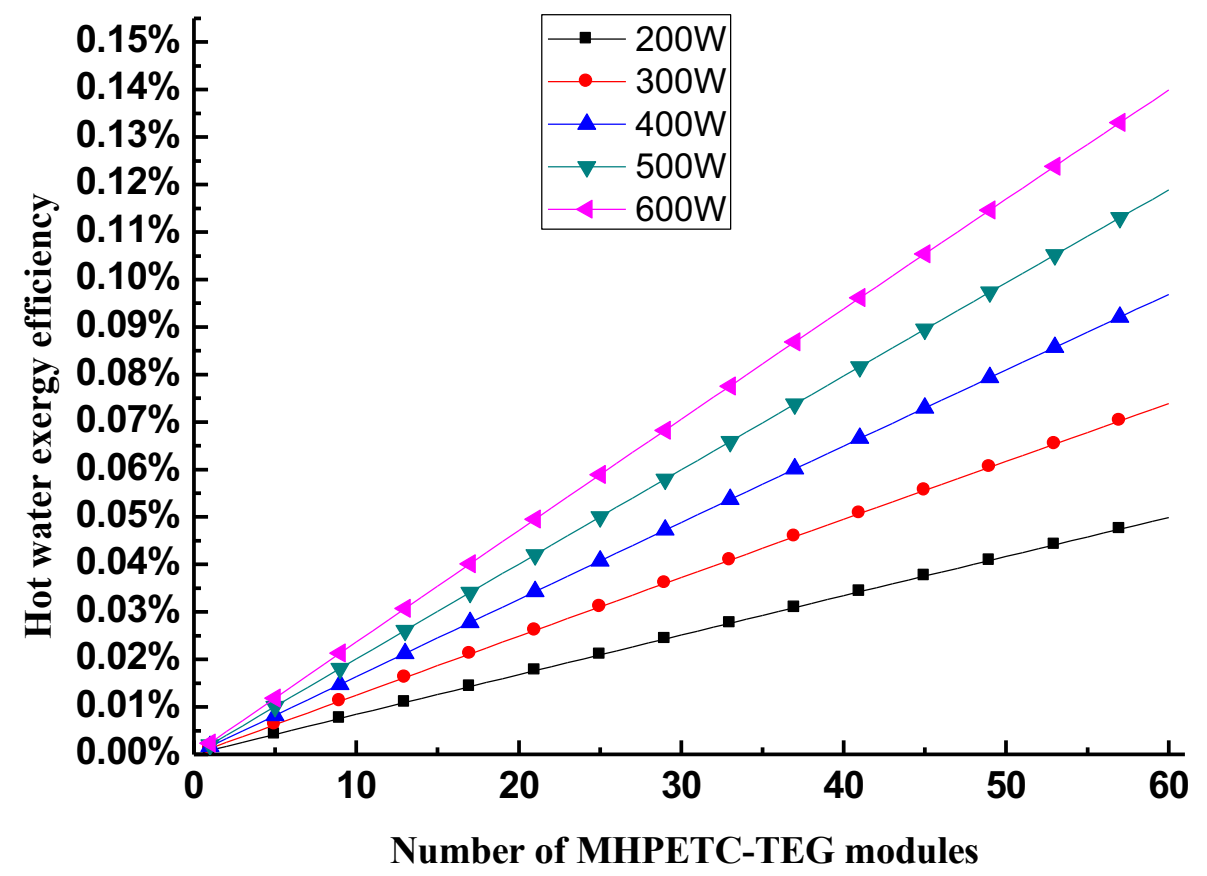

(a)

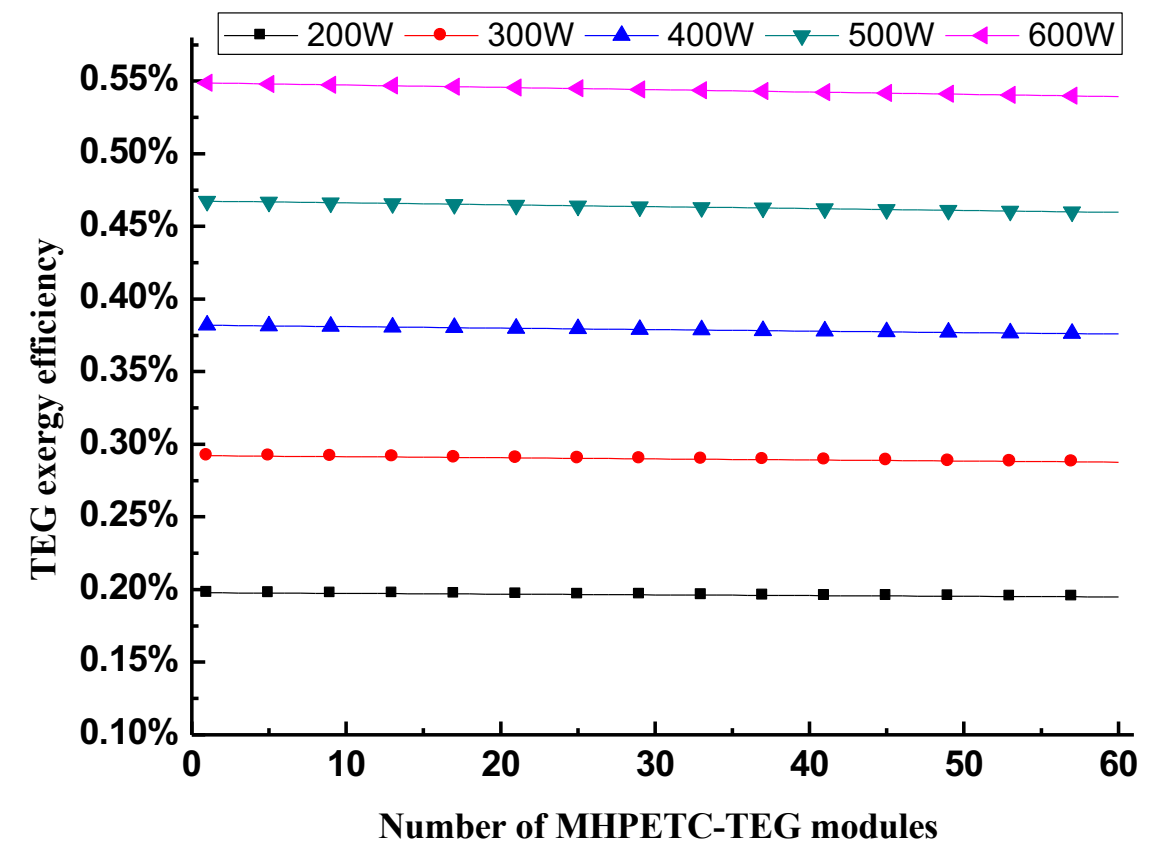

(b)

Figure 10.6 Exergy efficiency $\left(T_{i n}=25^{\circ} C, u_{f}=0.06 m / s\right)$ 


\section{b) Different flow rates}

When the water flow rate is low, the output water temperature is higher, and the increase tendency of the output water temperature is more when the number of MHPETC-TEG modules rise (Figure 10.7a). When the water flow rate increases, more energy can be taken by the cooling water, thus the selective absorbing coating temperature is lower than that with the low flow rate (Figure 10.7b). But it also can be seen that the temperature difference of the selective absorbing coating temperature will become small when the flow rate gradually increases.

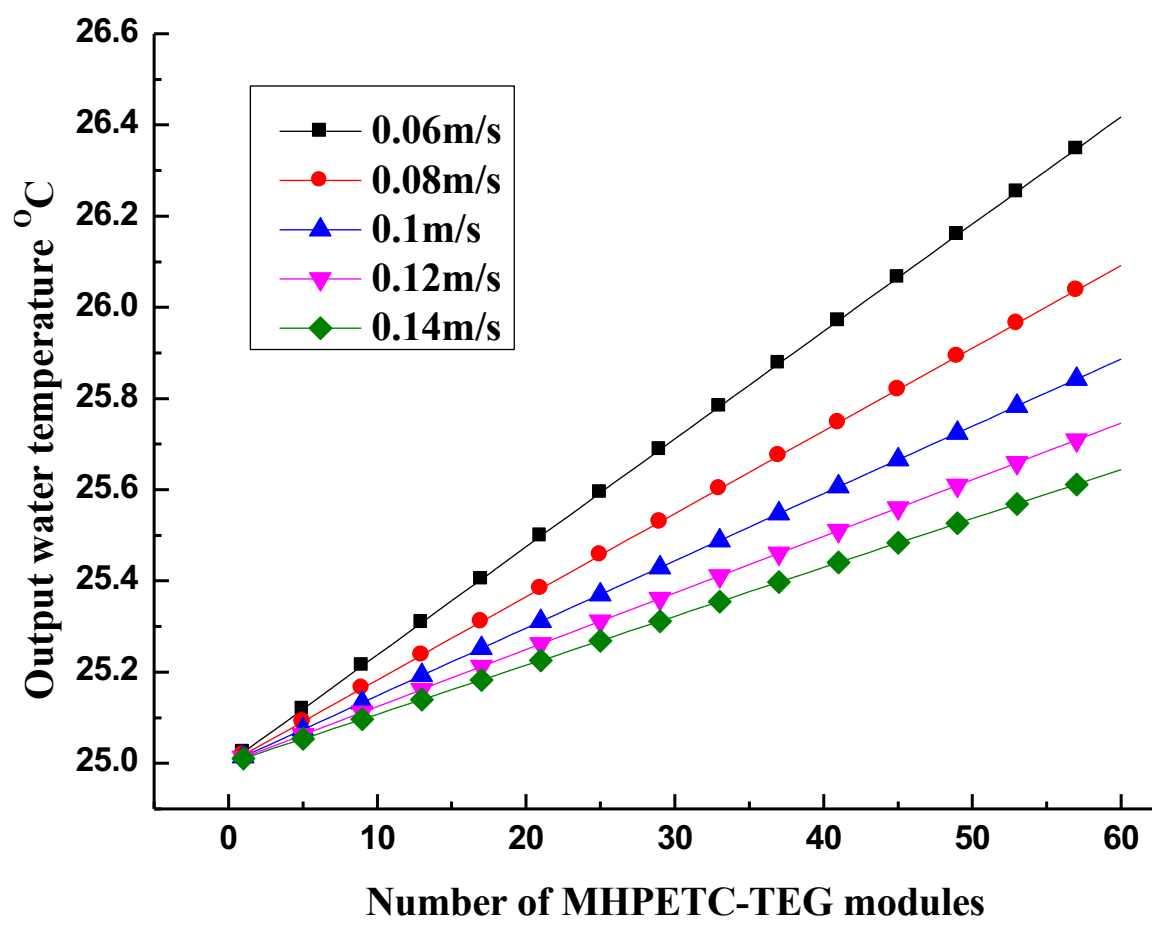

(a) 


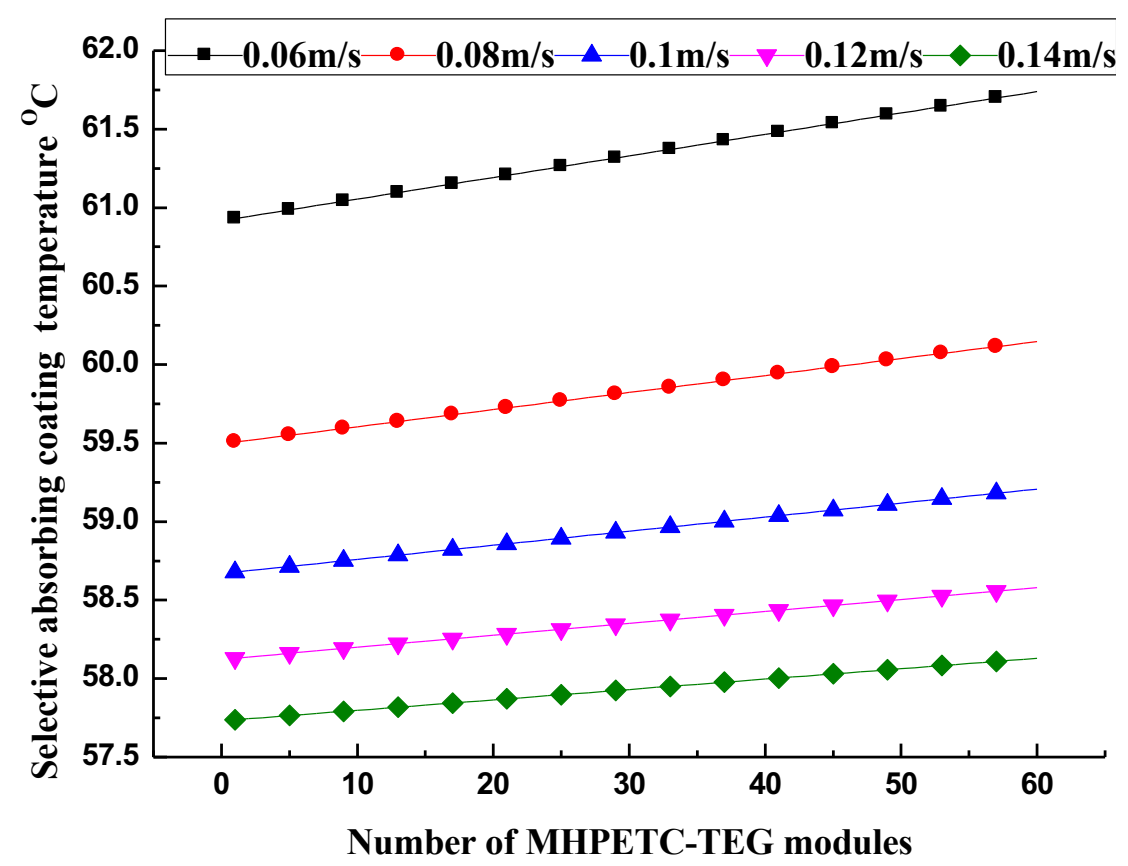

(b)

Figure 10.7 Temperature variation $\left(T_{\text {in }}=25^{\circ} C, G=600 \mathrm{~W}\right)$

The different flow rate of the water would also affect the performance of the solar collector. Figure 10.8 shows thermal efficiency and electrical efficiency based on the series of the flow rates. For flow rates within the range of 0.06 to $0.14 \mathrm{~m} / \mathrm{s}$, the high thermal performance and electrical performance respond to the high flow rate. It can be noticed that the high flow rate enhances the heat exchanger performance, and the thermal performance and electrical performance all reach above $64.0 \%$ and $0.67 \%$ respectively. 


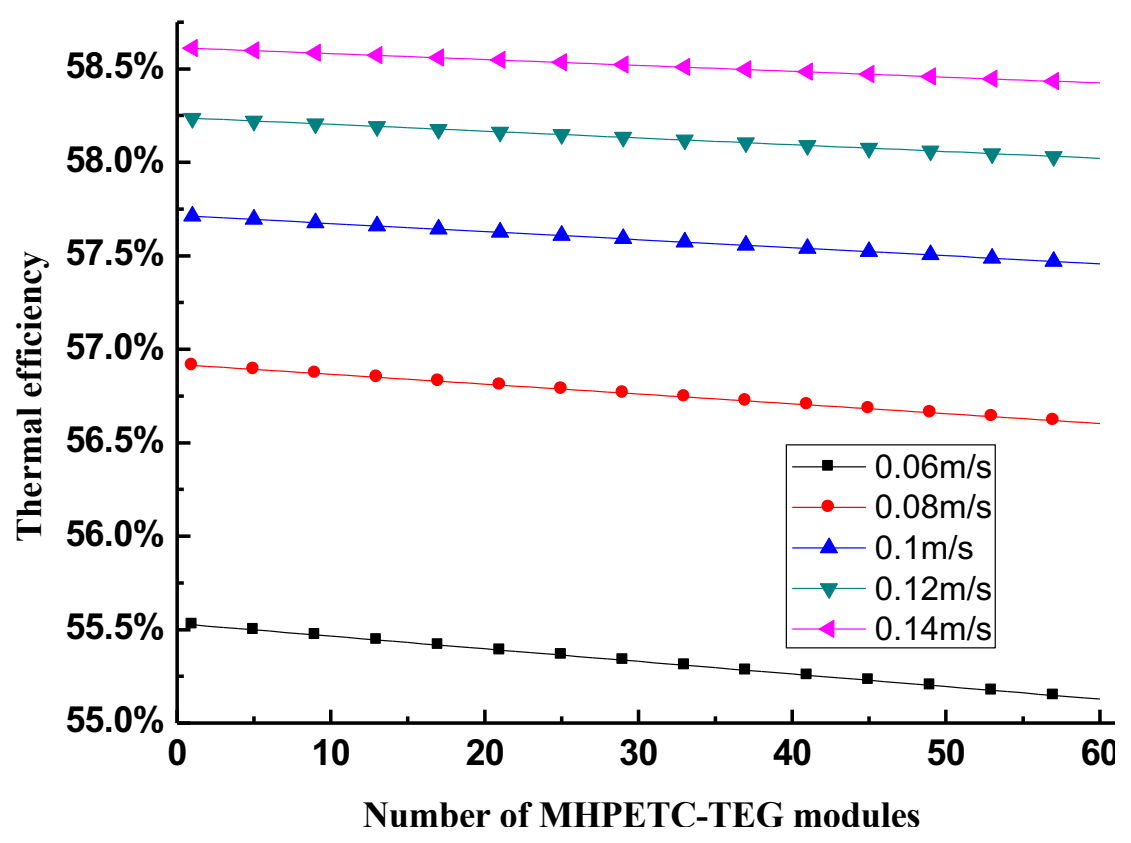

(a)

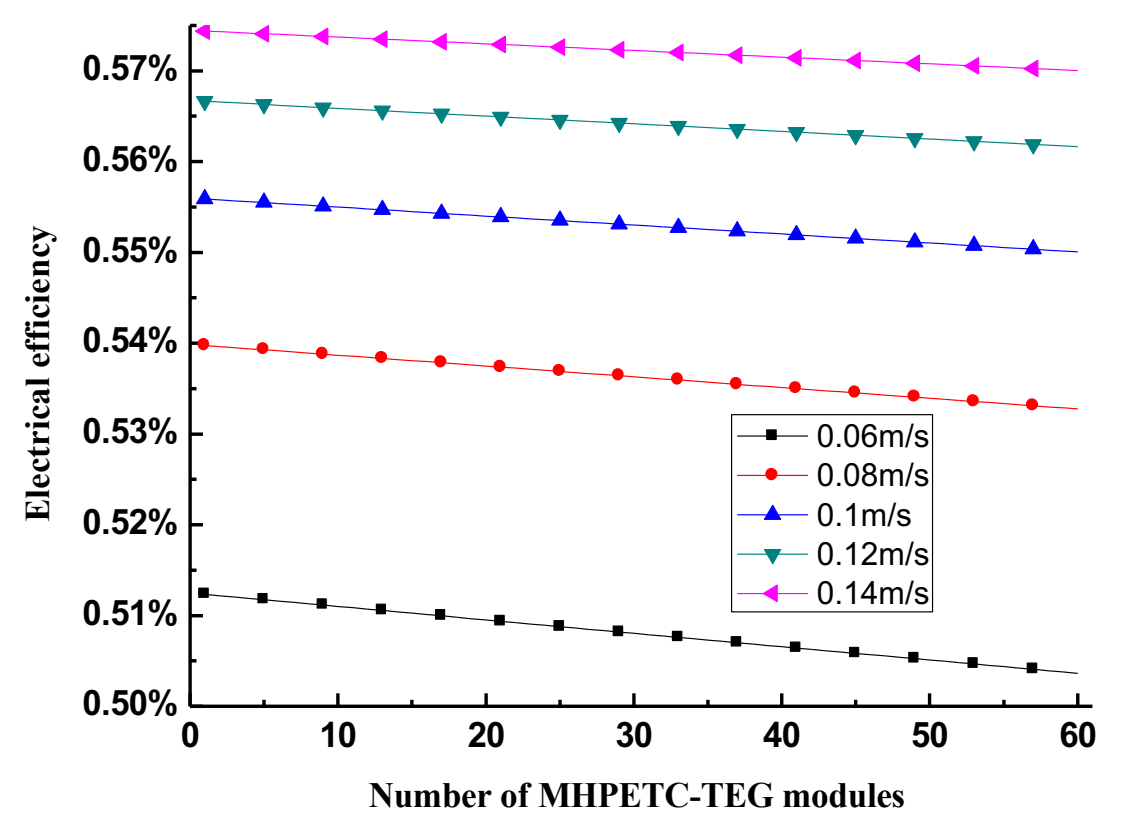

(b)

Figure 10.8 Thermal and electrical efficiency $\left(T_{i n}=25^{\circ} \mathrm{C}, G=600 \mathrm{~W}\right)$

For the hot water, the exergy efficiency has an increasing tendency which is different from the thermal efficiency and this is because the water temperature rises significantly (Figure 10.9). In addition, the low flow rate corresponds to the high exergy efficiency of the hot water. On the contrary, the exergy efficiency for the TEG can obtain a high value with the high flow rate. 


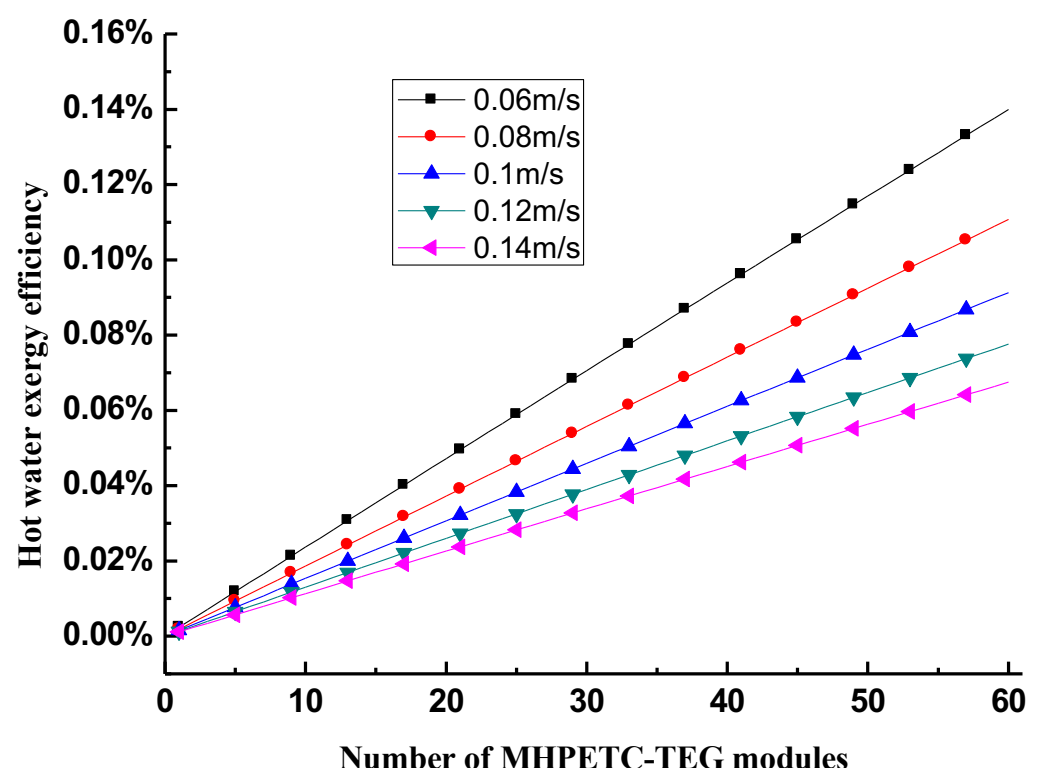

(a)

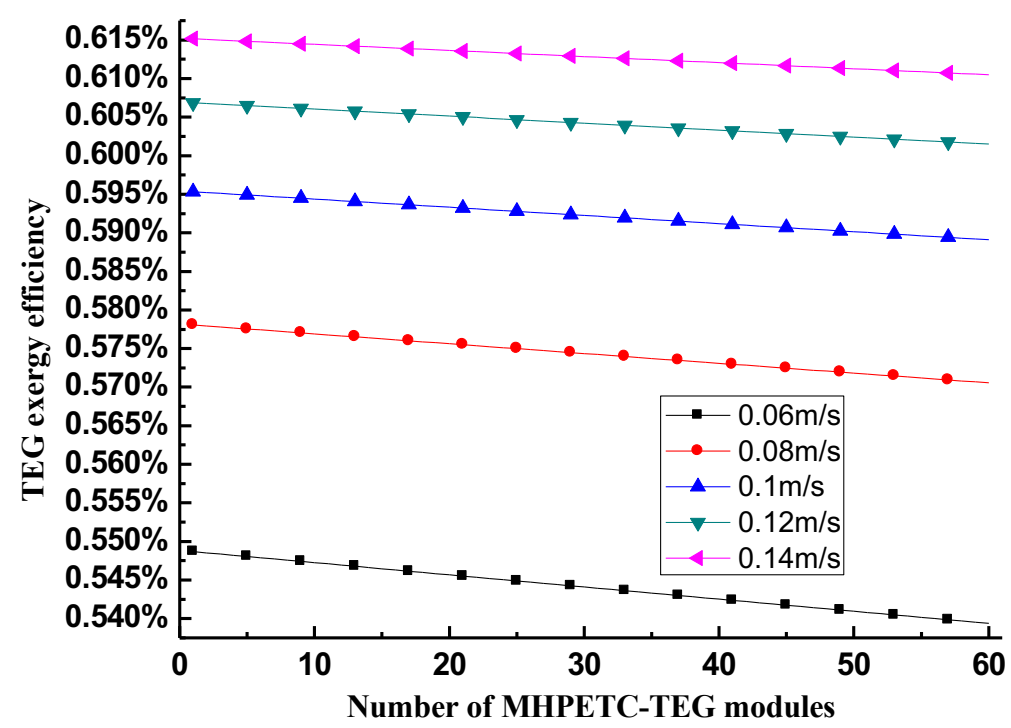

(b)

Figure 10.9 Exergy efficiency $\left(T_{i n}=25^{\circ} \mathrm{C}, G=600 \mathrm{~W}\right)$

\section{c) Different input temperature}

The higher input water temperature is corresponding to the lower thermal efficiency and electrical efficiency, since the higher input water temperature leads to the smaller temperature difference (Figure 10.10). However, even when the input temperature is $45^{\circ} \mathrm{C}$, the thermal efficiency is still above $43.0 \%$. 


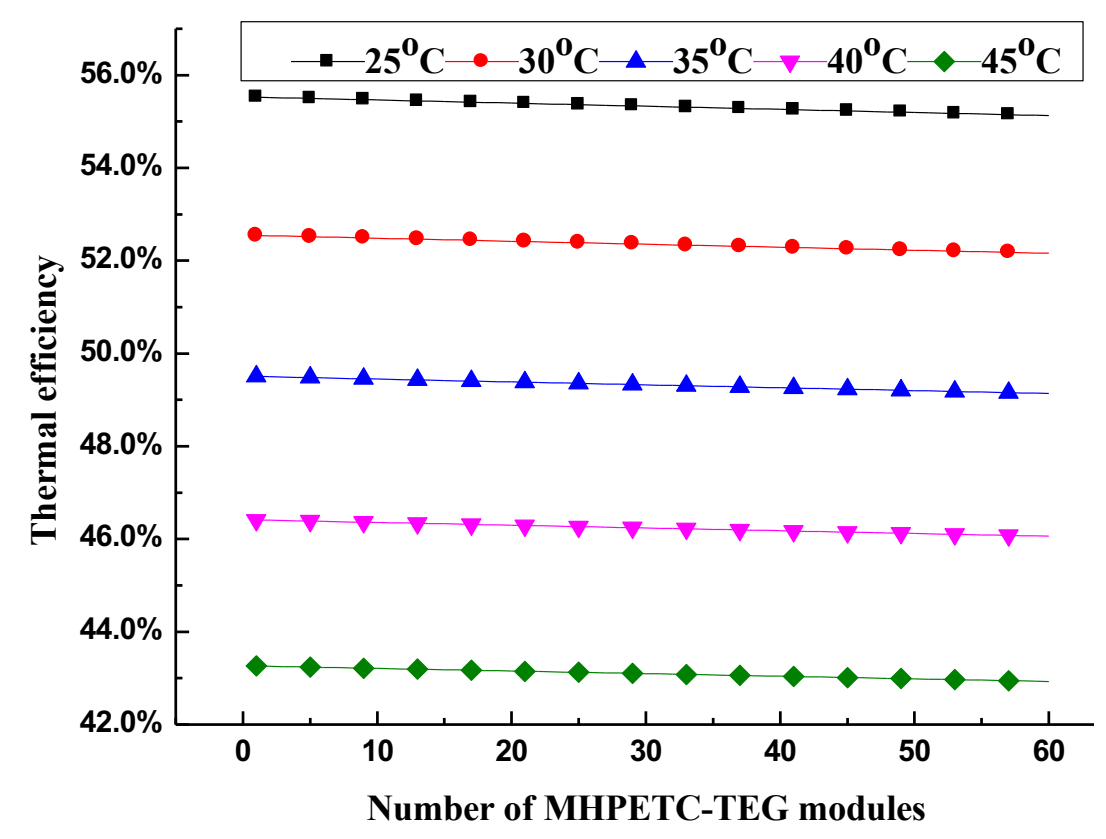

(a)

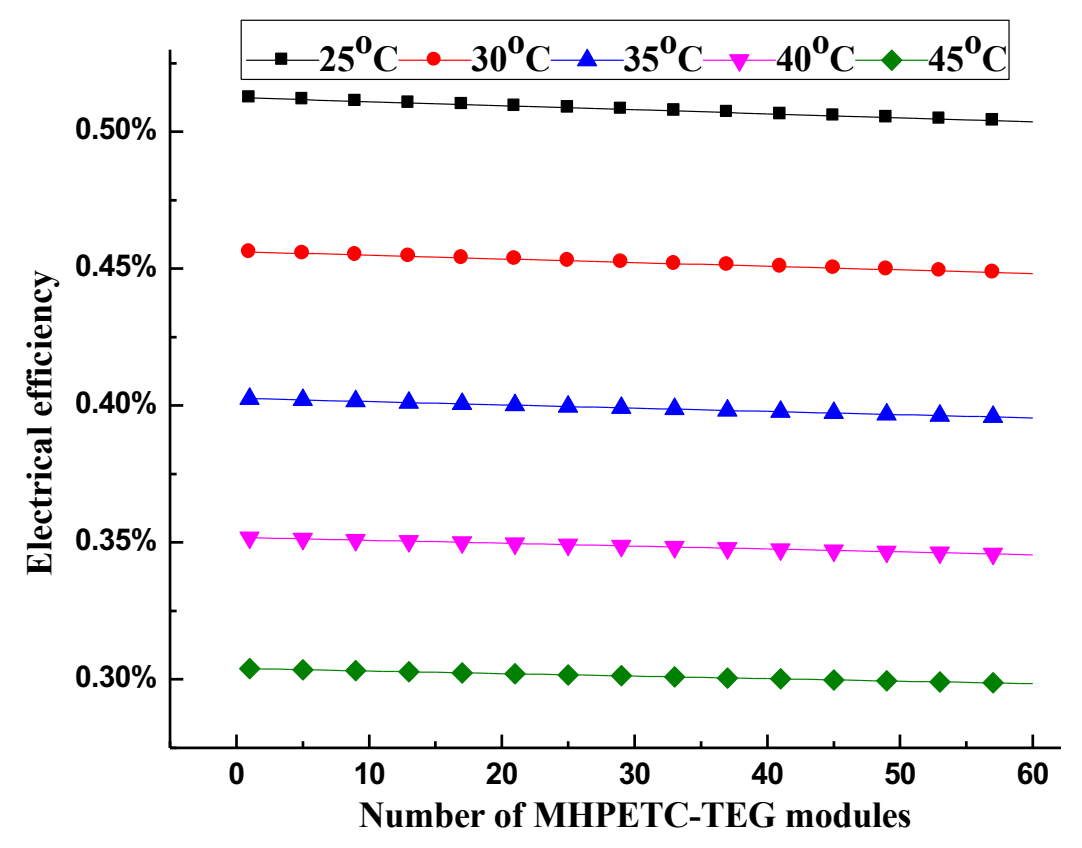

(b)

Figure 10.10 Thermal and electrical efficiency $\left(G=600 W, u_{f}=0.06 m / s\right)$

When the input water temperature increases, the exergy efficiency of the hot water has a significant increase (Figure 10.11a). When the input water temperature is $45^{\circ} \mathrm{C}$, the exergy efficiency is close to $3.0 \%$. On the other hand, with an increase in water temperature, the TEG exergy efficiency has a decreasing tendency, which results from the high water temperature leading to a low temperature difference between the hot and cold sides of TEG module. 


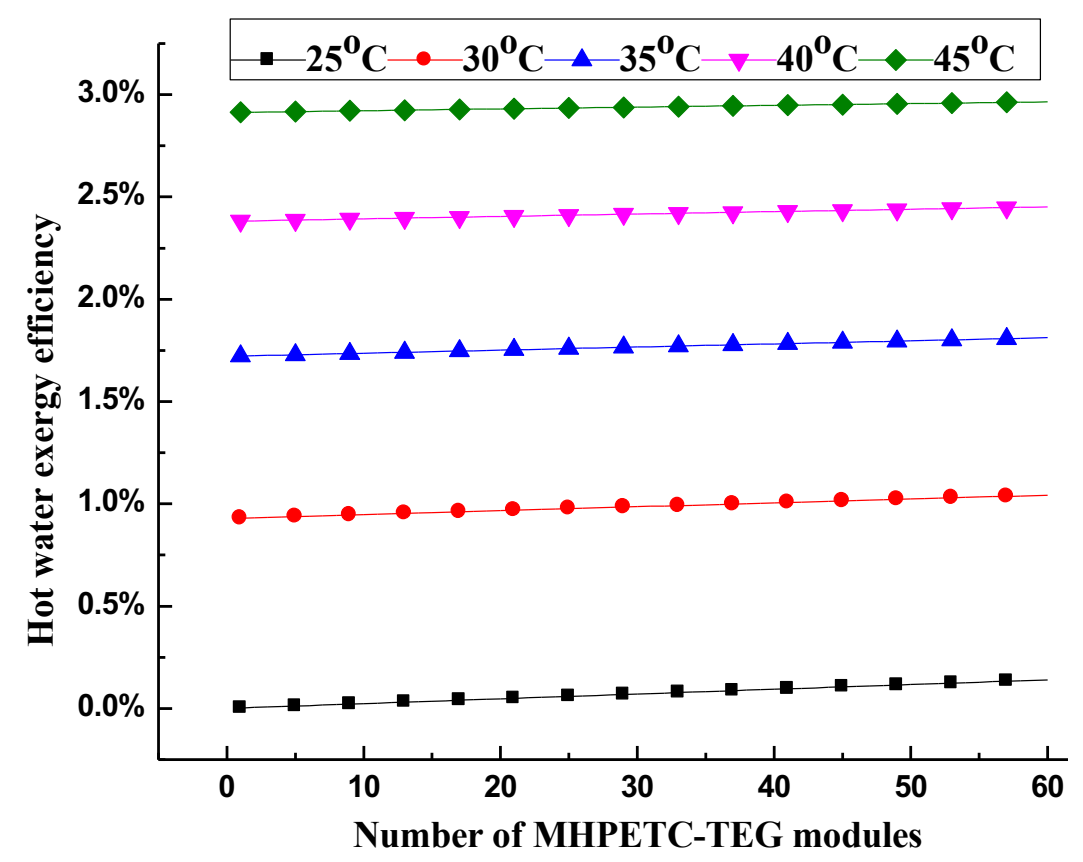

(a)

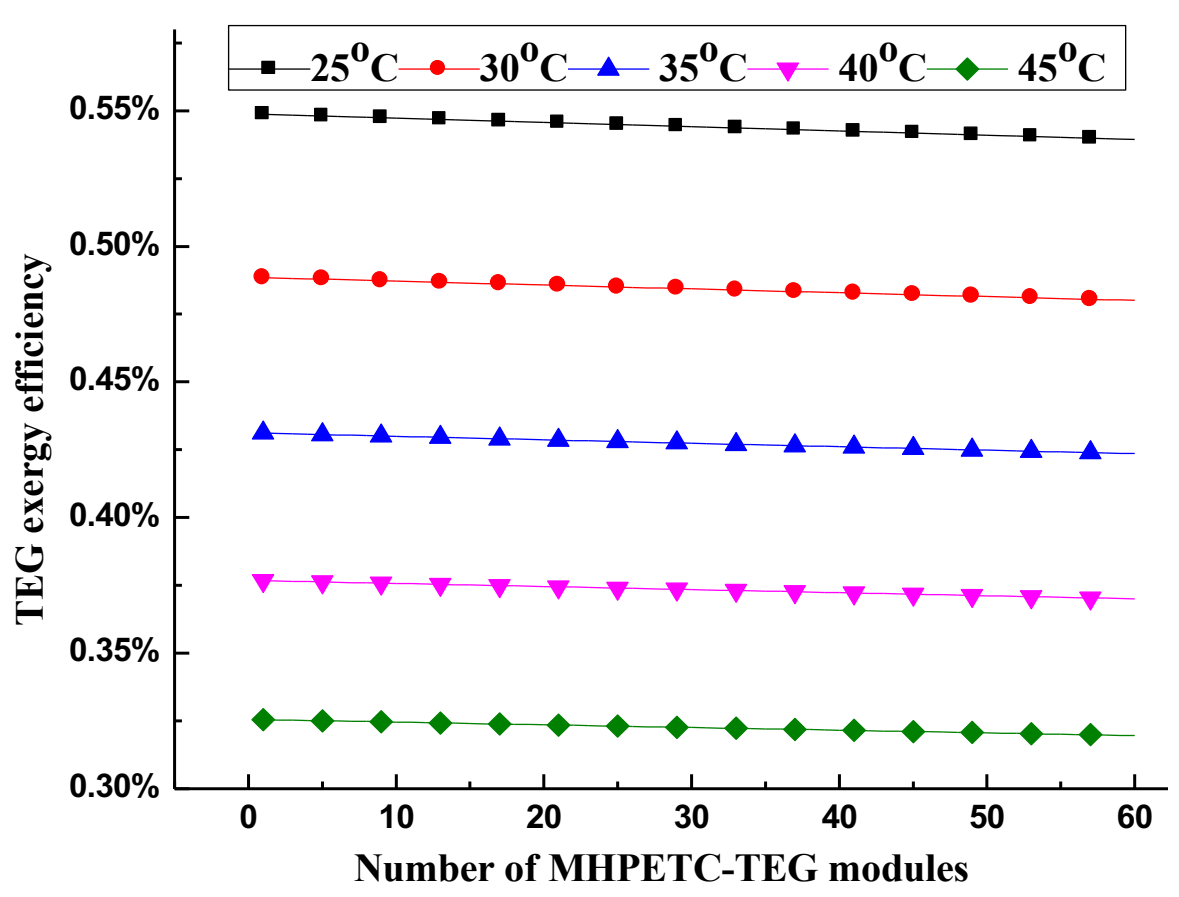

(b)

Figure 10.11 Exergy efficiency $\left(G=600 W, u_{f}=0.06 m / s\right)$

10.3.2 Solar concentrating thermoelectric generator using the micro-channel heat pipe array (STEG-MCHP) 


\section{A) STEG-MCHP introduction}

Solar selective absorbing coating is attached to the upper surface of the evaporator of the MCHP while the TE module is attached to the lower surface of the condenser (Figure 10.12). During operation, the solar heat imposed on the upper surface of the MCHP's evaporator is conveyed to its condenser, by means of evaporation of the working fluid within the MCHP. In the condenser, the heat is released via condensation of the MCHP working fluid and is then transferred to the attached TE modules. This creates a temperature gradient across the TE module, thus resulting in a thermal-to-electrical conversion by means of the 'Peltier effect'. The cooling structure of TEG is air cooling, and its performance is affected by the cooling structure, ambient temperature and wind speed.

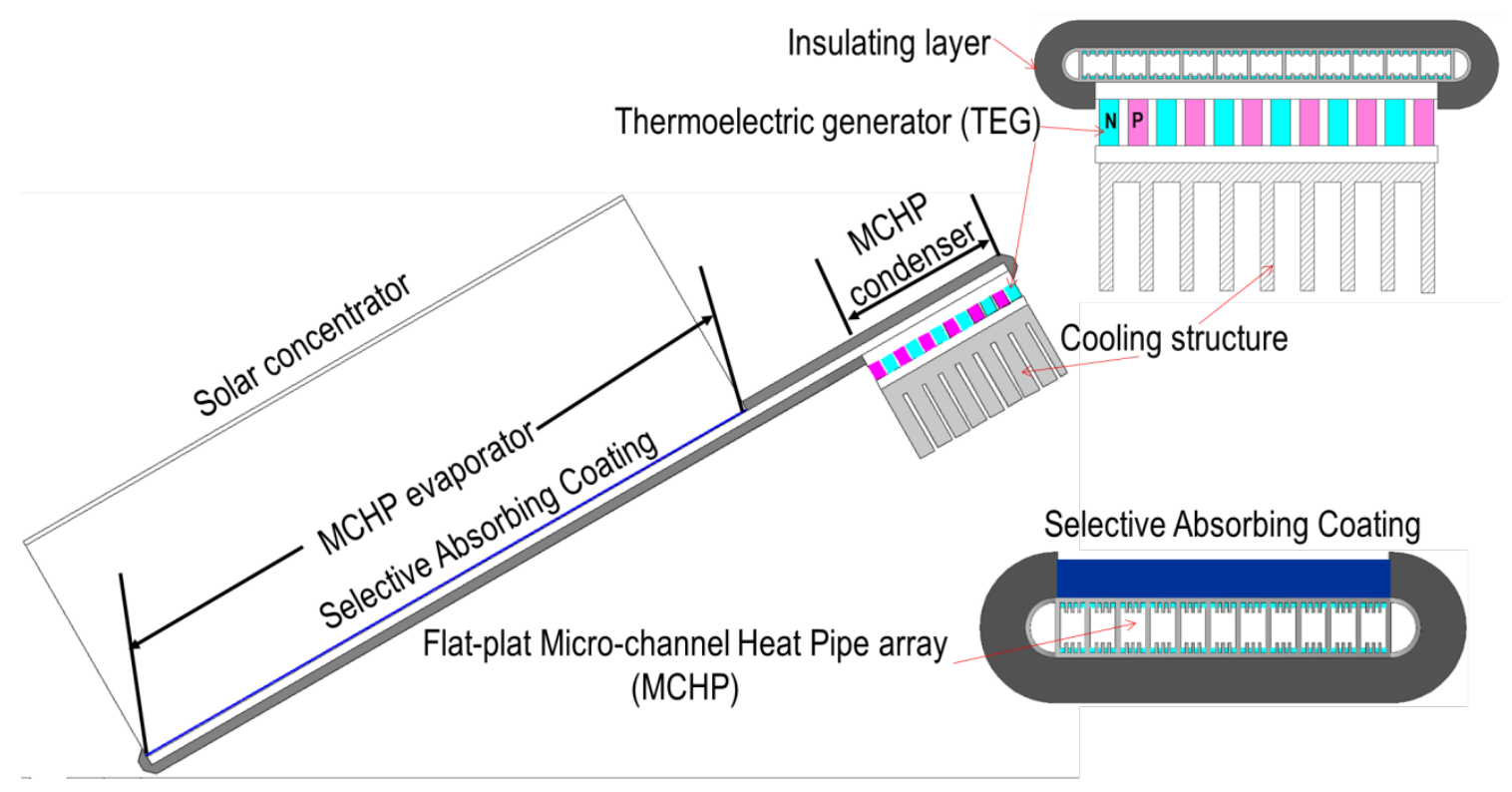

Figure 10.12 Schematic diagram of the STEG-MCHP system

In order to analyze the performance of the STEG-MCHP system, a preliminary experiment was conducted to verify the mathematical model. The main experiment and test elements are shown in Figure 10.13. The MCHP array is a flat aluminum plate with multiple parallel micro-channel heat pipes. The thickness of MCHP is $3.0 \mathrm{~mm}$ and each micro-channel heat pipe has many 
inner microgrooves (or micro-fins) to enhance heat transfer by repeated evaporation and condensation of inner working fluid. The solar linear Fresnel concentrator of $4 \mathrm{X}$ was chosen to obtain higher solar radiation. The TEG module was fabricated by ShenMingYang Electronics Ltd. (product code: TEG1-241-1.4-1.2). The size of the TEG was $55 \times 55 \times 3.4 \mathrm{~mm} 3$. In addition, the comparison between the STEG-MHCP and two TEGs in series was made. The two systems had the same area of the selective absorbing coating, which equaled to 2 times top surface area of one TEG. The relative parameters are shown in Table $\mathbf{1 0 . 1}$.

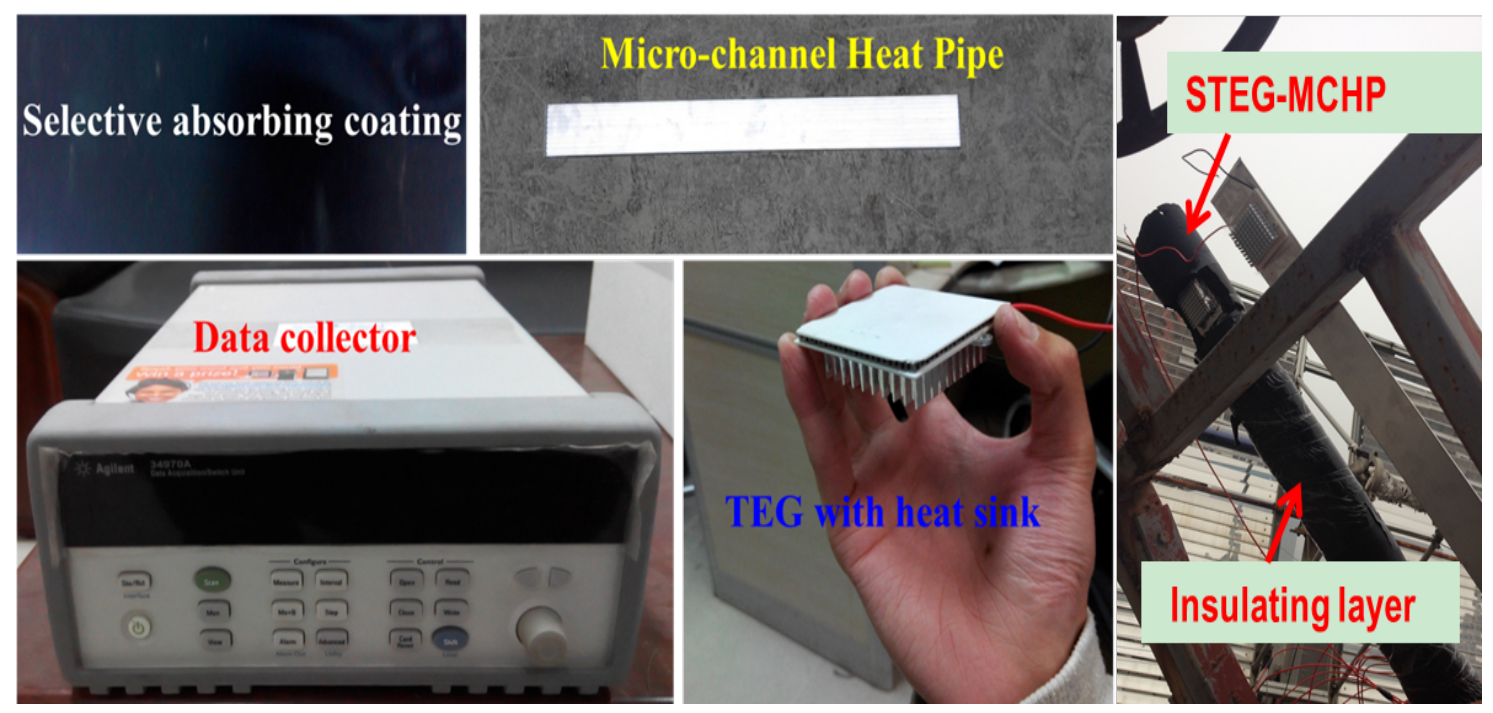

Figure 10.13 Photo of the main experiment and test elements

Table 10.1 Relative parameters in the experiment

\begin{tabular}{|l|c|}
\hline Parameter & Numerical \\
\hline Environment & $301.15 \mathrm{~K}$ \\
\hline Ambient temperature $\boldsymbol{T}_{\boldsymbol{a}}$ & $600 \mathrm{~W}$ \\
\hline Solar radiation $\boldsymbol{G}$ & 4 \\
\hline Concentration ratio $\boldsymbol{C}$ & $0.5 \mathrm{~m} / \mathrm{s}$ \\
\hline Ambient wind speed $\boldsymbol{u}$ & $5 \mathrm{~m} / \mathrm{s}$ \\
\hline Wind speed around heat sink $\boldsymbol{u}_{\text {wind }}$ & \\
\hline MCHP & $23000 \mathrm{~W} /(\mathrm{m} \cdot \mathrm{K})$ \\
\hline Thermal conductivity of heat pipe $\boldsymbol{K}$ & $0.75 \mathrm{~m}$ \\
\hline Length of the heat pipe $\boldsymbol{L}_{\boldsymbol{h} \boldsymbol{p}}$ & \\
\hline
\end{tabular}




\begin{tabular}{|c|c|}
\hline $\begin{array}{l}\text { Thermal contact resistance between TEG and } \\
\text { heat sink } \boldsymbol{R}_{\boldsymbol{c t} \mathbf{3}}\end{array}$ & $1 \times 10^{-4} \Omega$ \\
\hline \multicolumn{2}{|l|}{ Selective absorbing coating } \\
\hline Absorptivity of the absorbing coating $\boldsymbol{\alpha}_{\boldsymbol{b}}$ & 0.93 \\
\hline Area of selective absorbing coating $\boldsymbol{A}$ & $0.00605 m^{2}$ \\
\hline Reflectivity of the absorbing coating $\boldsymbol{\varepsilon}$ & 0.8 \\
\hline $\begin{array}{l}\text { Thermal contact resistance between selective } \\
\text { absorbing coating and heat pipe } \boldsymbol{R}_{\boldsymbol{c t} \mathbf{1}}\end{array}$ & $4 \times 10^{-4} \Omega$ \\
\hline $\begin{array}{l}\text { Thermal contact resistance between heat pipe and } \\
\text { the TEG } \boldsymbol{R}_{\boldsymbol{c t} \mathbf{2}}\end{array}$ & $1 \times 10^{-4} \Omega$ \\
\hline \multicolumn{2}{|l|}{ TEG } \\
\hline Numbers of $\mathrm{P}$ or $\mathrm{N}$ junction $\boldsymbol{\eta}_{\boldsymbol{t e g}}$ & 241 \\
\hline Cross-section area of one $\mathrm{P}$ or $\mathrm{N}$ junction $\boldsymbol{a}_{\boldsymbol{t e g}}$ & $1 \times 10^{-8} m^{2}$ \\
\hline Seebeck coefficient $\boldsymbol{\alpha}_{\boldsymbol{t e g}}$ & $1.35 \times 10^{-4} V / K$ \\
\hline Electrical resistivity of one $\mathrm{P}$ or $\mathrm{N}$ junction $\boldsymbol{r}_{t e g}$ & $3.35 \times 10^{-8} \Omega / \mathrm{m}$ \\
\hline Height of TEG $\boldsymbol{l}_{\boldsymbol{t e g}}$ & $3.4 \times 10^{-3} \mathrm{~m}$ \\
\hline \multicolumn{2}{|l|}{ Heat sink } \\
\hline Height of the heat sink $\boldsymbol{H}$ & $1 \times 10^{-2} \mathrm{~m}$ \\
\hline Length of the heat sink $\boldsymbol{L}$ & $5 \times 10^{-2} \mathrm{~m}$ \\
\hline Cross section area of the heat sink $\boldsymbol{S}_{\mathbf{1}}$ & $1.2 \times 10^{-4} \mathrm{~m}^{2}$ \\
\hline Total area of the fins $\boldsymbol{S}_{2}$ & $1.46 \times 10^{-2} \mathrm{~m}^{2}$ \\
\hline
\end{tabular}

To measure their temperature, thermocouples were attached to the different surfaces, and the temperature readings were obtained from the data logger. The output of the TEG module was connected to the electronic load which had an adjustable resistance. The current and the voltage values of the load resistance were collected by the ammeter and voltmeter. The uncertainty of the thermocouples, the ammeter and the voltmeter are listed in the Table 10.2.

Table 10.2 Uncertainty of the equipment 


\begin{tabular}{|l|l|}
\hline Test Equipment & Uncertainty \\
\hline Voltmeter & $\pm 0.5 \%$ \\
\hline Ammeter & $\pm 0.8 \%$ \\
\hline Thermocouple & $0.2-0.5 \mathrm{~K}$ \\
\hline
\end{tabular}

\section{B) STEG-MCHP Performance analysis}

From Figure 10.14, it can be seen that the maximum temperature difference value between the simulation and experiment was within $2^{\circ}$ Cand the temperature difference between the MCHP's evaporator and condenser was within $1.5^{\circ} \mathrm{C}$. Therefore, the simulation results fitted well with experiment values. Besides this, it can also be observed that the temperature difference of the MCHP's evaporator and condenser is small.

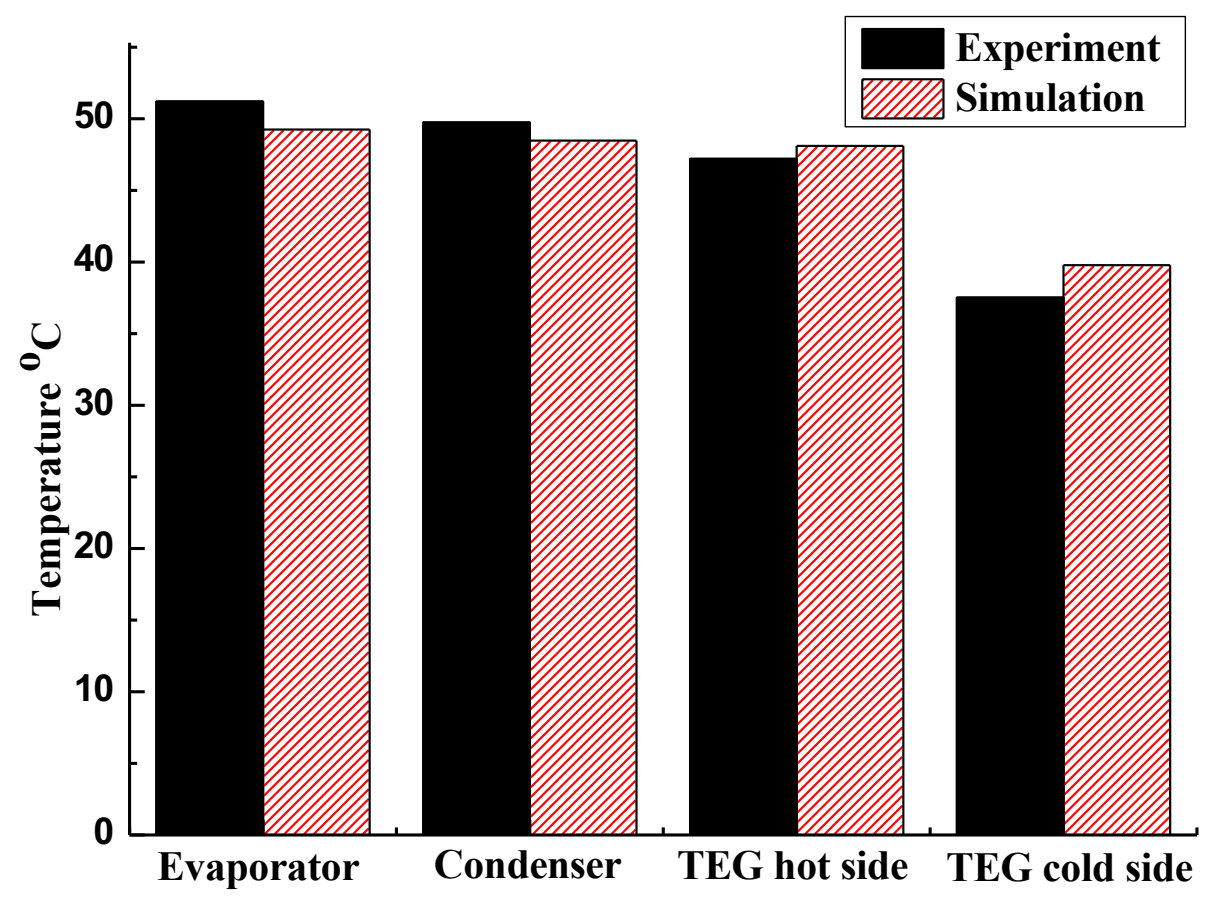

Figure 10.14 Temperature comparison between experiment and simulation

It is clear from Figure 10.15 that the output power of the STEG-MCHP system was higher than that of two TEGs in series, which means the STEG-MCHP system maybe have a higher output with less TEG module and lower cost. 


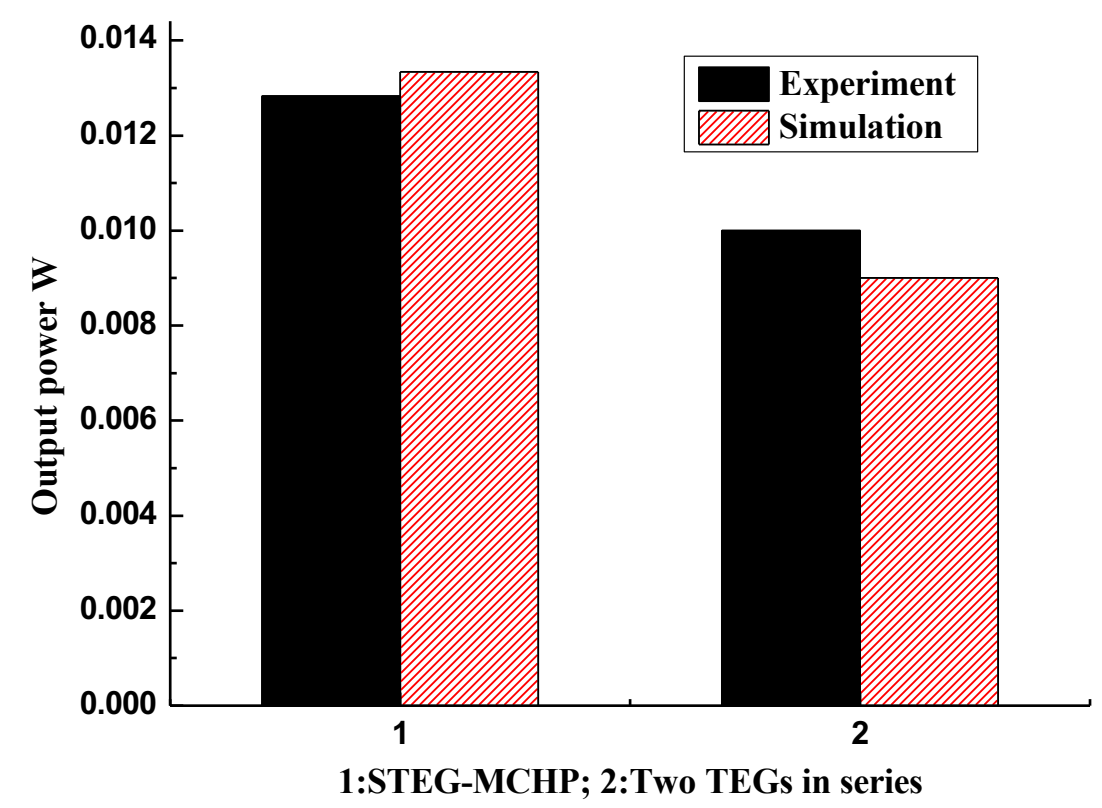

Figure 10.15 Comparison of output power between STEG-MCHP and two TEGs in series

\section{a) Different areas of selective absorbing coating}

In order to keep the same areas of the selective absorbing coating of the STEG-MCHP system and the TEGs in series directly, the area of selective absorbing coating should be the integer multiples for one TEG module. The ambient wind speed equals to that around the heat sink. The solar radiation and the concentration ratio were set to $1000 \mathrm{~W} / \mathrm{m}^{2}$ and $4 \mathrm{X}$. The ambient temperaturewas $25^{\circ} \mathrm{C}$.

It can be seen from Figure $\mathbf{1 0 . 1 6}$ that in this ambient condition, when the area of the selective absorbing coating is larger than $2 * 0.055^{*} 0.055 \mathrm{~m}^{2}$, the STEG-MCHP has the higher temperature difference, which also presents the advantage of MCHP that concentrates heat to the condenser. 


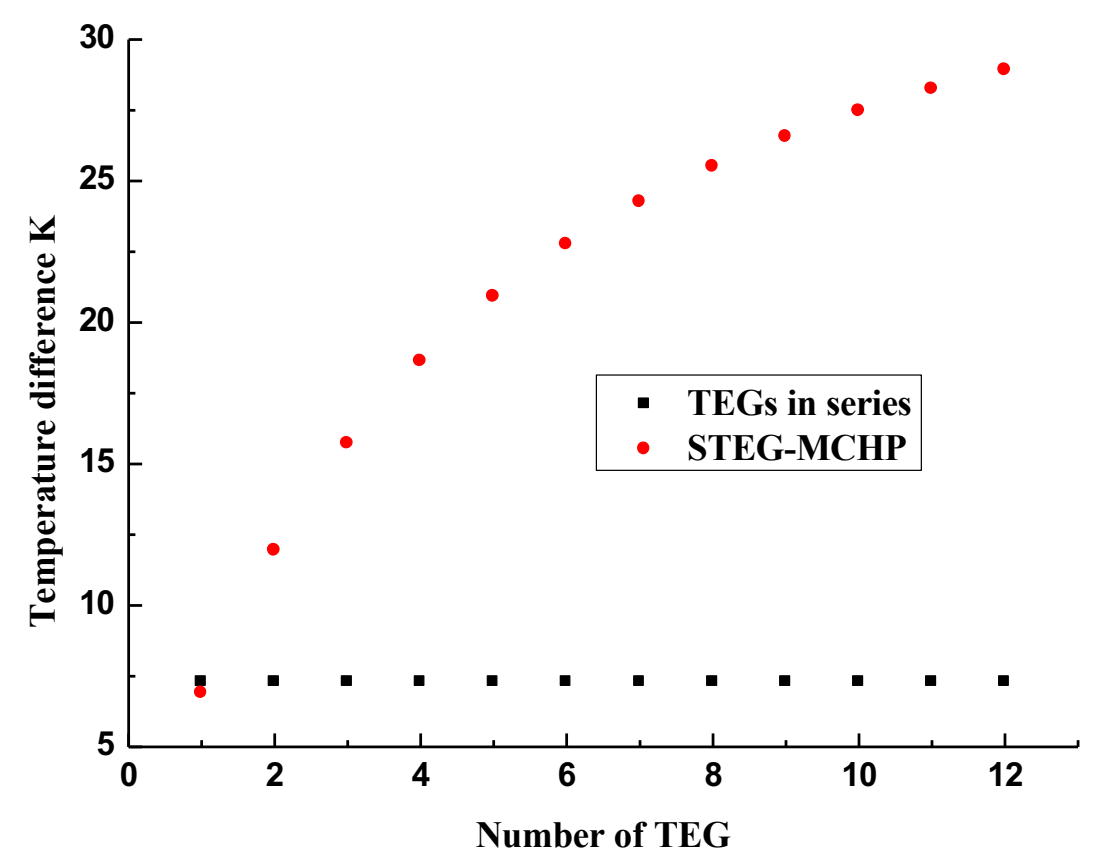

Figure 10.16 Temperature difference with different areas of selective absorbing coating Form Figure 10.17, it is clear that the STEG-MCHP system has a higher output power when the number of TEG is larger than 2, and the reason for this is that the STEG-MCHP has the larger temperature difference, which also responds to the higher electrical efficiency. But it can also be seen that the increase tendency on output power of STEG-MCHP becomes alleviated.

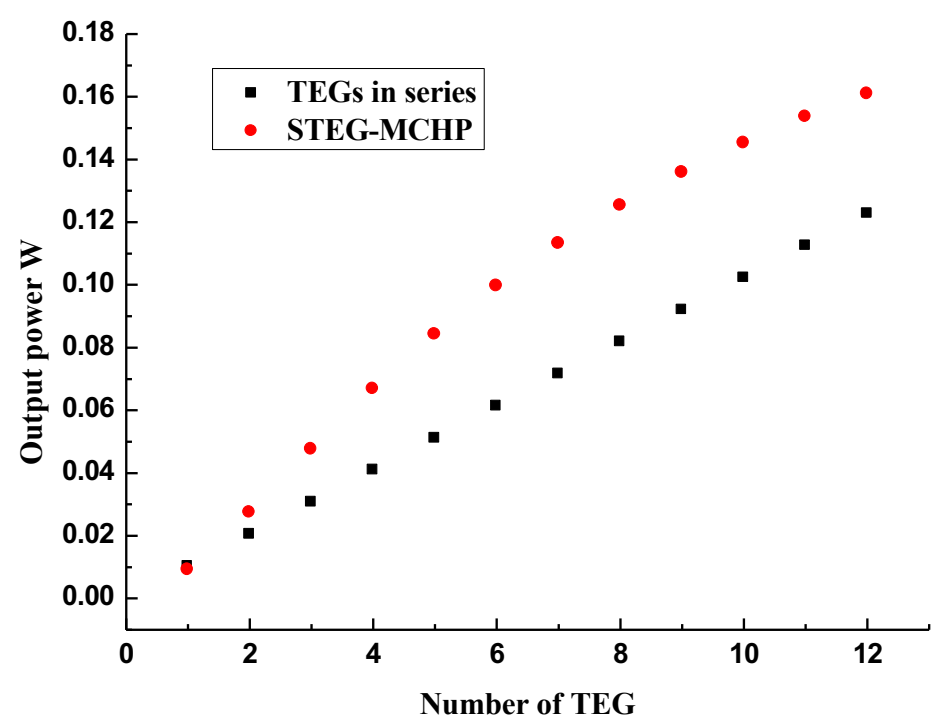

Figure 10.17 Output power with different areas of selective absorbing coating

\section{b) Different concentration ratio}

It can be seen from Figure $\mathbf{1 0 . 8}$ that with the increase of the concentration ratio, the electrical 
efficiencies of the STEG-MCHP and the TEGs in series can all be improved. However, on one specific concentration ratio, the electrical efficiency of the STEG-MCHP shows an initial increase then decrease tendency, which is different from the TEGs in series which show a nearly constant tendency. Furthermore, when the selective absorbing coating area is about $5^{*} 0.055^{*} 0.055 \mathrm{~m}^{2}$, the electrical efficiency may get a peak value, and this is because with the increase of the selective absorbing coating area, the temperature of the MCHP would be increased, and this leads to larger thermal losses.

In addition, it can be predicted that if the temperature limit of the MCHP is not considered, or if the MCHP can operate in the middle temperature, the electrical efficiency of MCHP would have a lower value than TEGs in series. Therefore, the STEG-MCHP has an advantage than TEGs in series, but the advantage would exist in a certain range. Besides this, it also can be seen that the electrical efficiencies in Figure 10.18 are all low, which is because the largest temperature difference between the hot side and cold side of TEG is below $30{ }^{\circ} \mathrm{C}$.

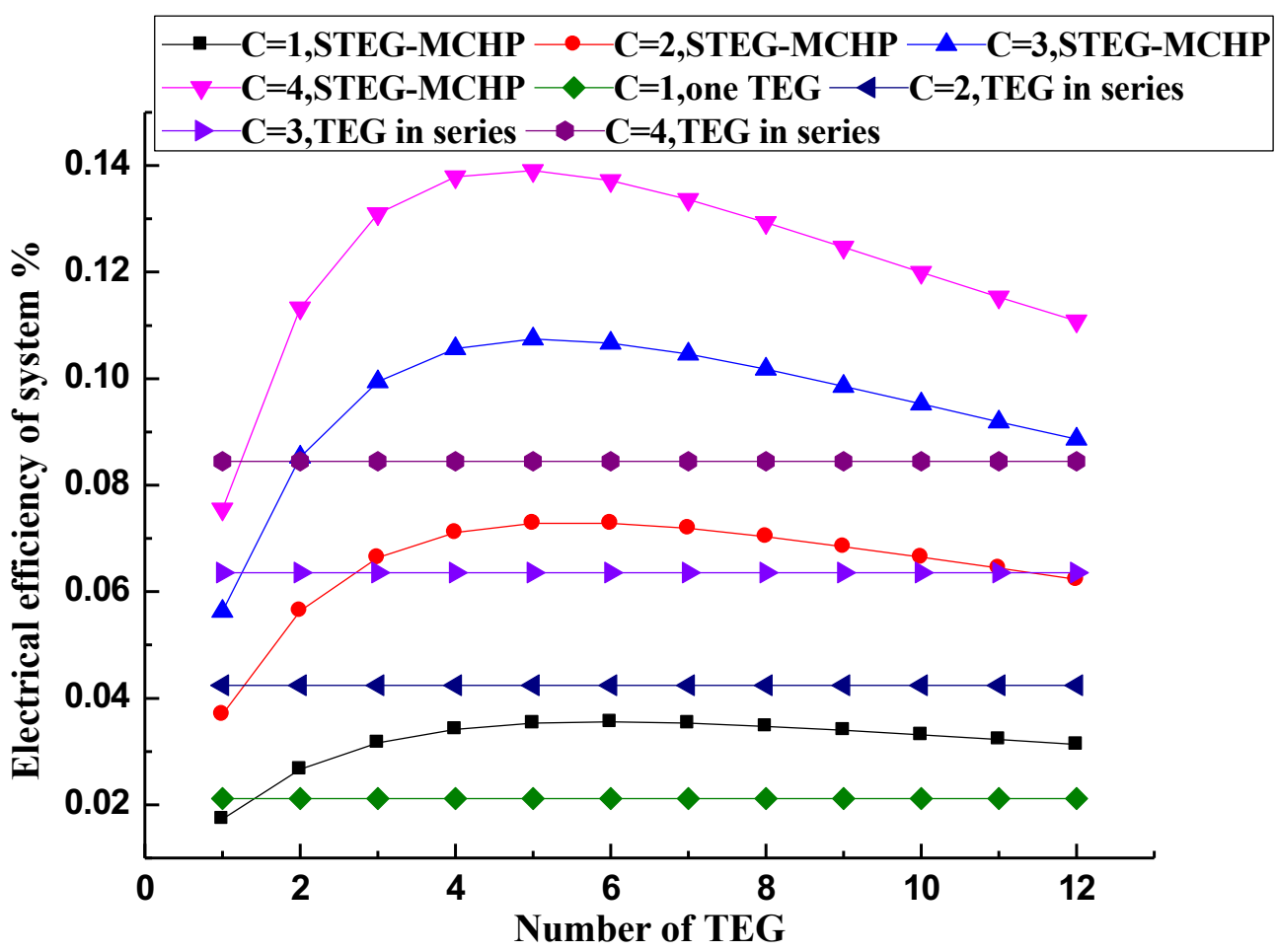

Figure 10.18 Electrical efficiency with series of concentration ratios 


\section{c) Different ambient temperatures}

Different ambient temperatures can affect the output performance, so different ambient temperatures such as $0^{\circ} \mathrm{C}, 25^{\circ} \mathrm{C}, 35^{\circ} \mathrm{C}$ were employed to analyze the electrical power with $3 \mathrm{X}$ concentration ratio (Figure 10.19).

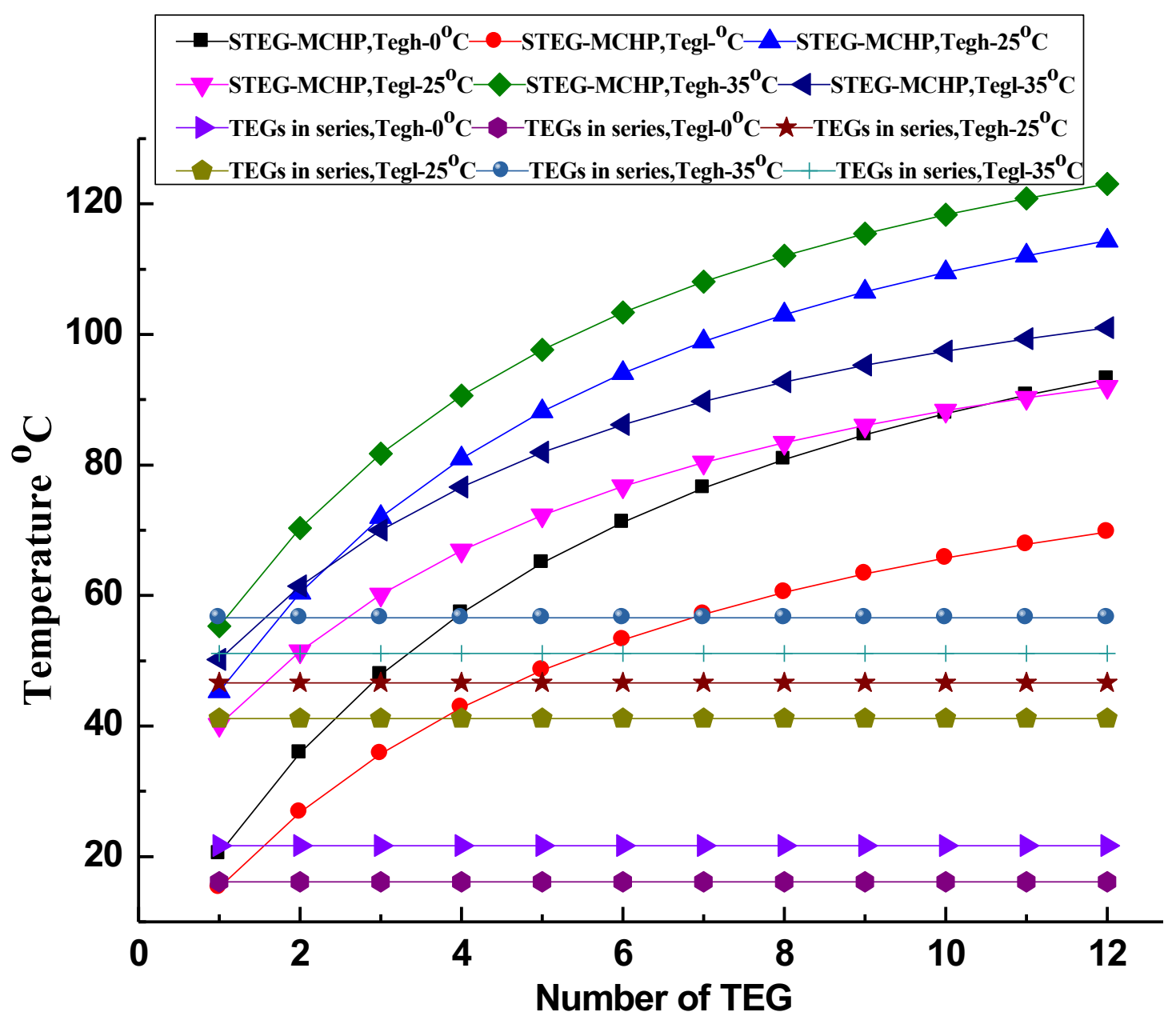

Figure 10.19 Hot side and cold side temperature with different ambient temperature

It is clear that with the higher ambient temperature, the hot side and cold side temperatures of TEG would all be higher. For the selective absorbing coating, the losses will be reduced, but for the TEG, the high temperature of cold side will lead to a negative impact on the output power.

For the STEG-MCHP system, the effect of the ambient temperature is significant, and the difference of the output power among the different ambient temperatures became obvious with 
the area increase of the selective absorbing coating (Figure 10.20). However, for the TEGs in series, the differences of the output power among the different ambient temperatures are relatively small. It must also be mentioned that the differences in output power between the STEG-MCHP and TEGs in series initially became larger then smaller.

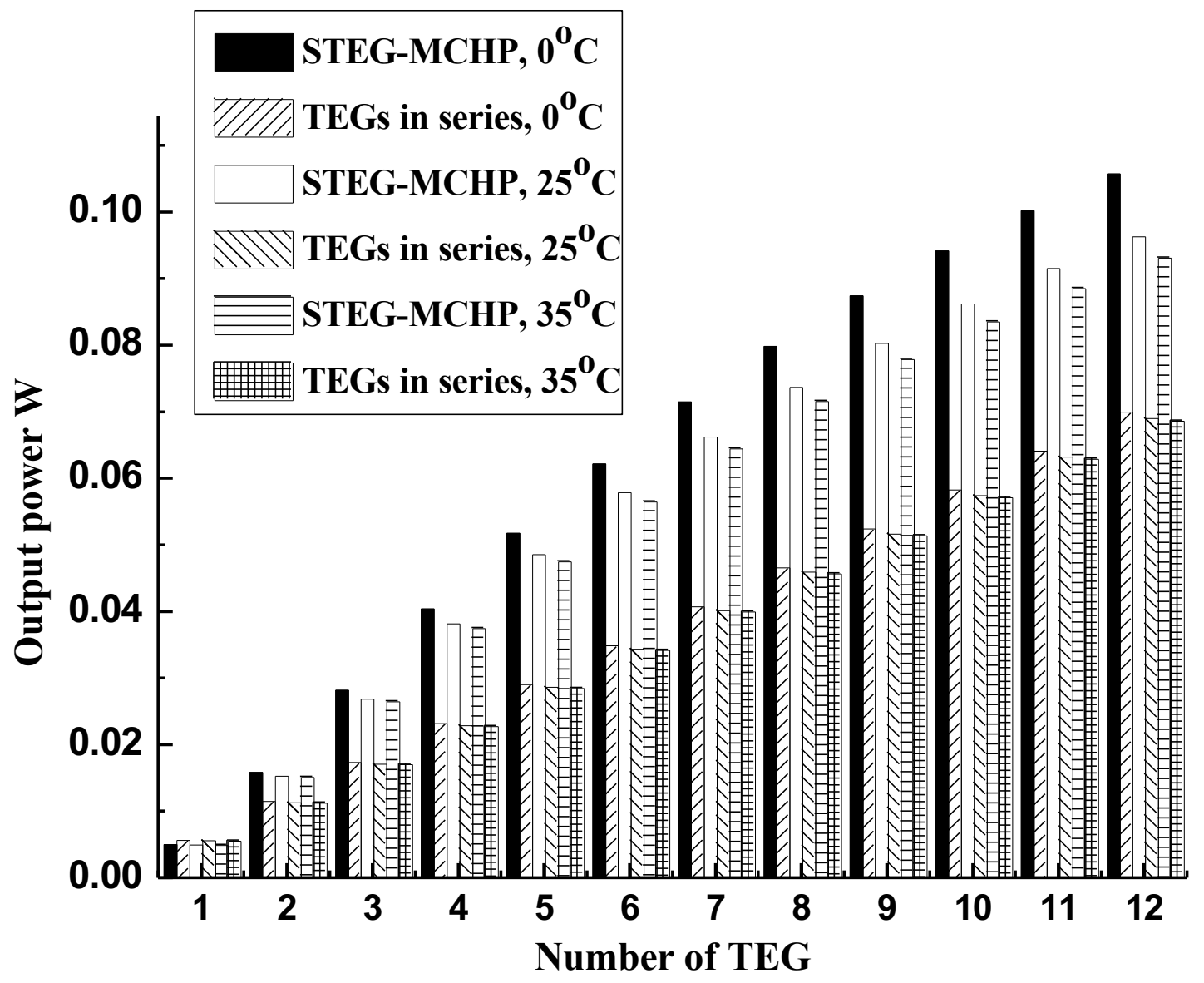

Figure 10.20 Output power with different ambient temperatures

\section{d) Different wind speeds}

The ambient temperature is set as $25^{\circ} \mathrm{C}$, and the wind speed is set as $1,2,3,4,5,6,7,8 \mathrm{~m} / \mathrm{s}$ respectively.

The temperature difference with $3 \mathrm{X}$ concentration ratio is shown in Figure 10.21. For STEGMCHP system, when wind speed is $1 \mathrm{~m} / \mathrm{s}$, the temperature difference between the hot side and cold side of TEG is lowest, which means the electrical efficiency of the TEG is lowest (Figure 10.21 (a)).However, the maximum temperature difference appears when the wind speed is 4 $\mathrm{m} / \mathrm{s}$, so there is a coupling relationship between the wind speed and the area of the selective 
absorbing coating.

For the TEGs in series, the maximum temperature difference appears when wind speed is $3 \mathrm{~m} / \mathrm{s}$ (Figure 10.21 (b)). The large wind speed can lead to a large temperature difference, but it can also cause a large amount of heat loss.

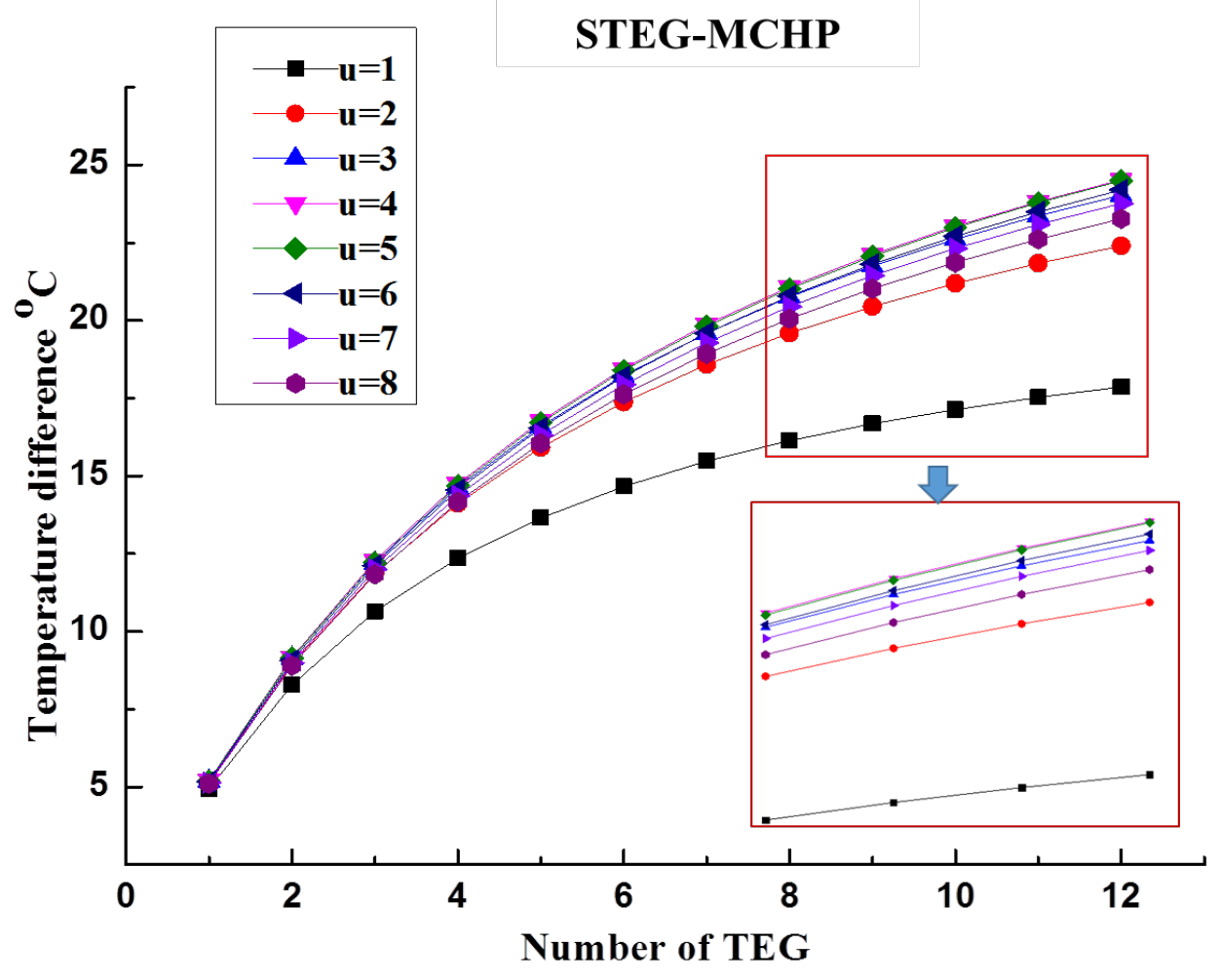

(a) 


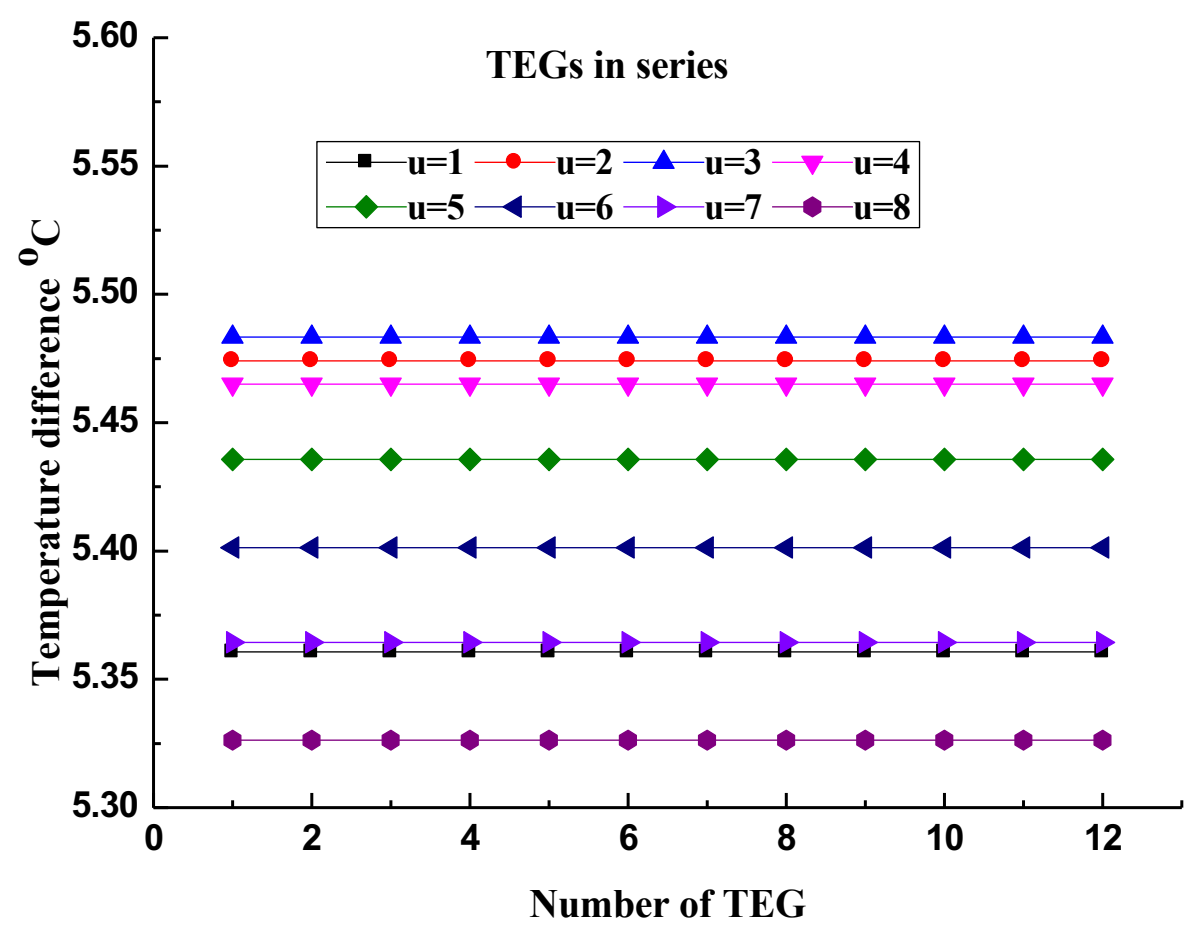

(b)

Figure 10.21 Temperature difference with different wind speeds

With the increase of the wind speed, the heat losses and the efficiency of the TEG all will be improved. At the same time, the temperature of the MCHP will also be reduced, which will have a higher concentration ratio and will also not reach the temperature limit of the MCHP. Figure 10.22 shows the TEG efficiency with the wind speed of $8 \mathrm{~m} / \mathrm{s}$. 


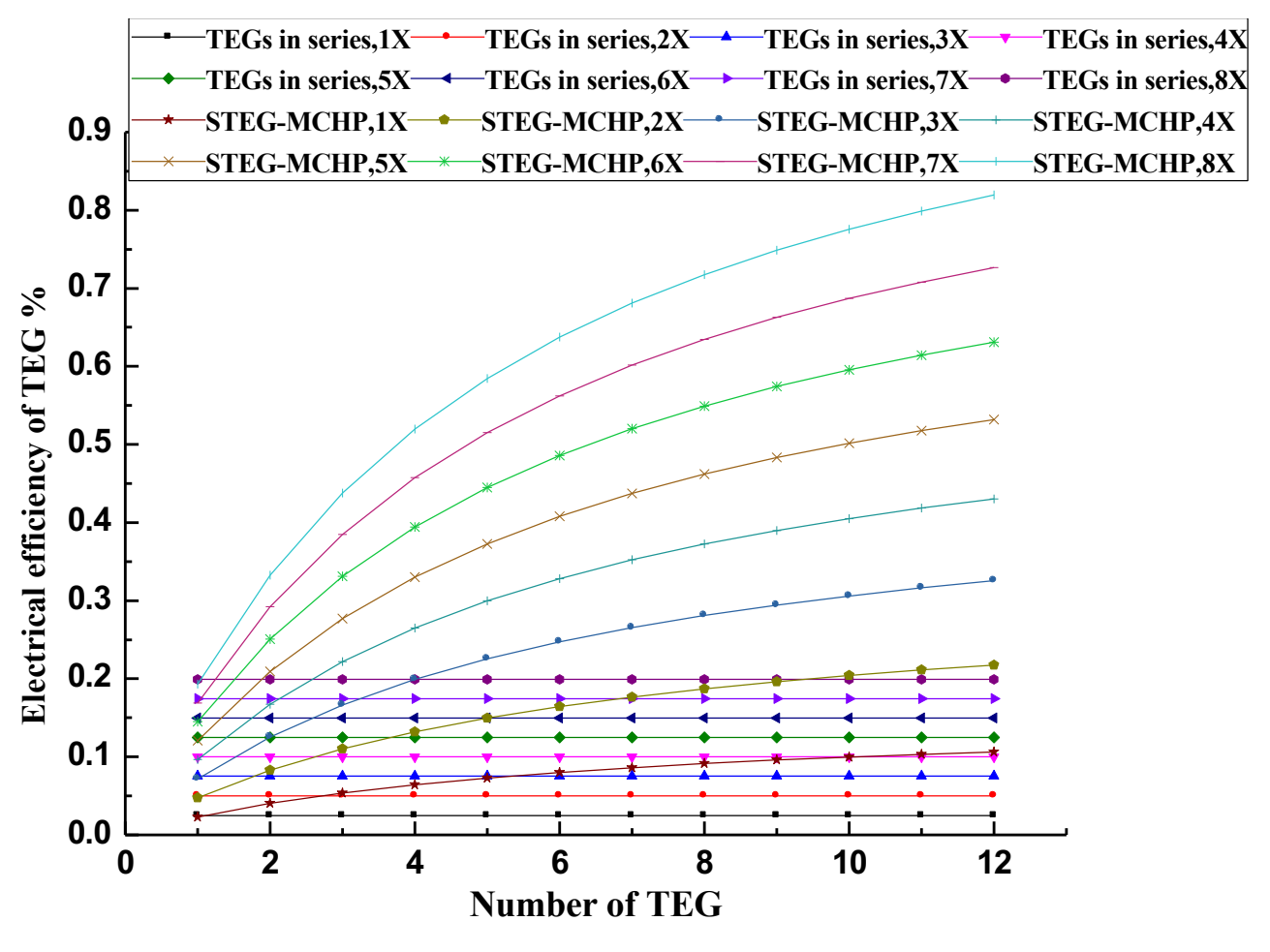

Figure 10.22 Electrical efficiency of TEG with the wind speed of $8 \mathrm{~m} / \mathrm{s}$

It can be seen that with the wind speed of $8 \mathrm{~m} / \mathrm{s}$, the electrical efficiency of TEG is improved significantly. In addition, with larger concentration ratio, the electrical efficiency has a larger value. For example, with the concentration ratio of $8 X$, the electrical efficiency of TEG has about $0.82 \%$ based on the temperature difference of $59.6^{\circ} \mathrm{C}$. However, for the whole system, the electrical efficiency is different from this. Taking the STEG-MCHP system with concentration ratio of $8 \mathrm{X}$ as an example, the system has its largest efficiency when the area of selective absorbing coating is $5^{*} 0.055^{*} 0.055 \mathrm{~m}^{2}$, which is because the larger area can also lead to larger heat losses.

\subsubsection{Novel photovoltaic-thermoelectric system (PV-TE)}

\section{A) PV-TE introduction}

The novel photovoltaic-thermoelectric system is shown in Figure 10.23. The PV modules were attached to the upper surface of the evaporator of the MCHP while the TE modules were attached to the lower surface of the condenser. During operation, solar energy was imposed on PV modules on the upper surface of the MCHP's evaporator, then the thermal energy was 
conveyed to MCHP's condenser, by means of the evaporation of the working fluid within the MCHP. In the condenser, the heat was released via condensation of the MCHP working fluid and was then transferred to the attached TE modules. This created a temperature gradient across the TE module, thus resulting in a thermal to electrical conversion by means of the 'Peltier effect'. The cooling structure of TEG was air cooling, and its performance was affected by the cooling structure, the ambient temperature and the wind speed.

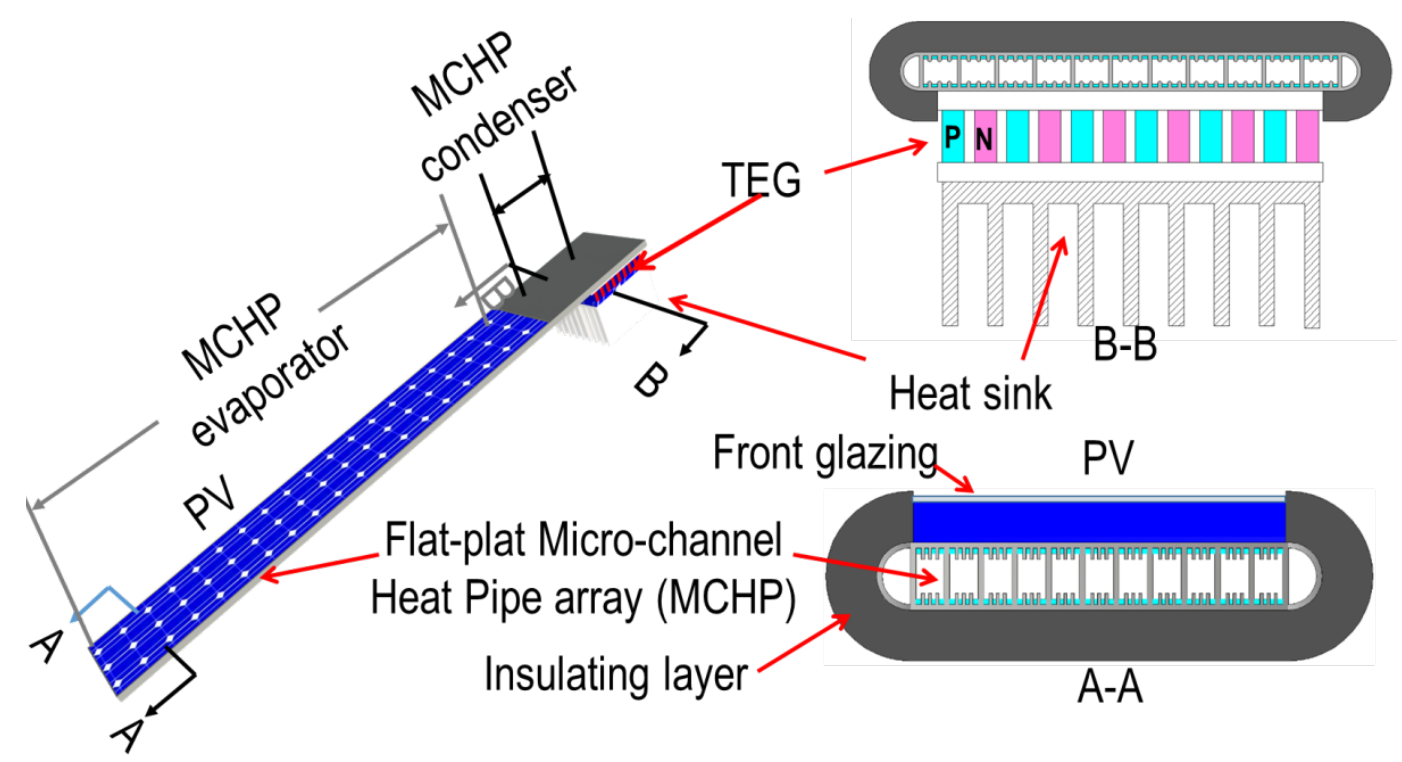

Figure 10.23 Schematic diagram of the novel photovoltaic-thermoelectric system

\section{B) PV-TE Performance Analysis}

The performance of the new PV-TE system was affected by the ambient parameters. In this section, different solar radiation, wind speed and ambient temperature were all considered to illustrate the PV-TE performance. In addition, the conventional PV system was also compared to this new system.

\section{a) Different solar radiation}

When the wind speed was $2 \mathrm{~m} / \mathrm{s}$ and the ambient temperature was $298 \mathrm{~K}$, the TEG hot and cold side temperature is shown in Figure 10.24. With the solar radiation increase, the temperature difference of TEG showed a rise tendency. 


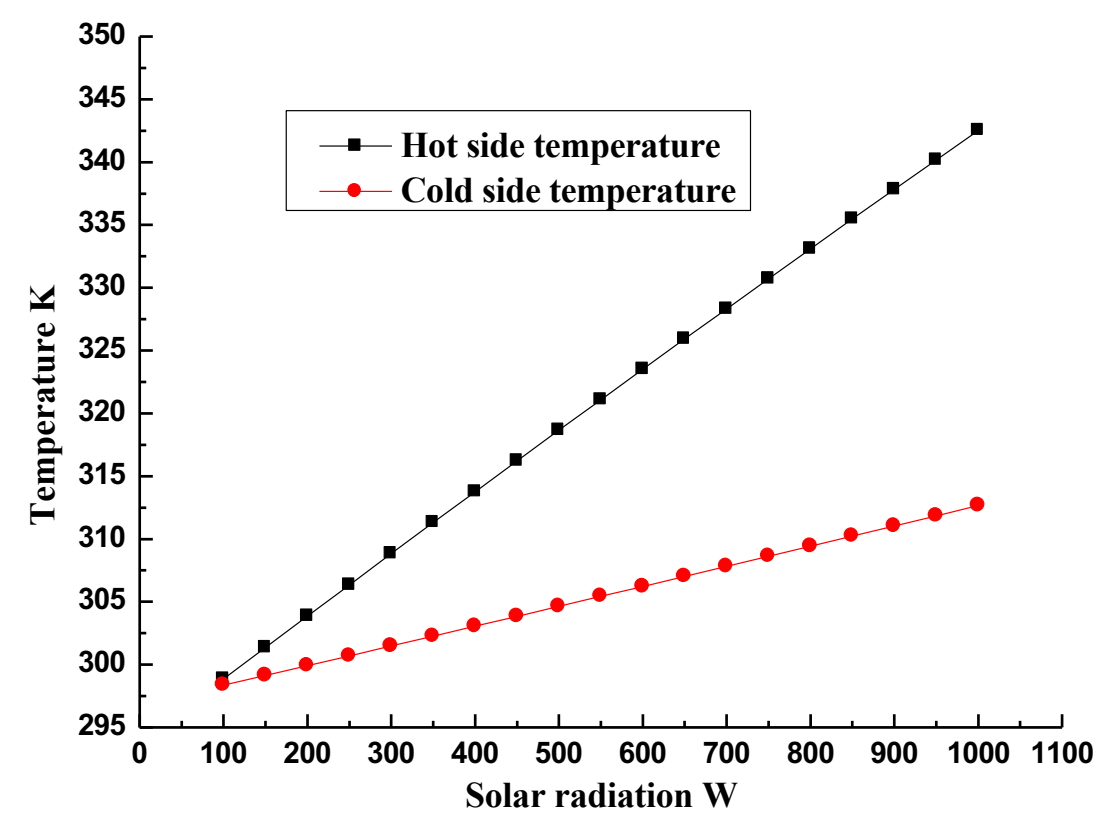

Figure 10.24 TEG hot and cold side temperature at different solar radiation

Corresponding to Figure 10.24, when the solar radiation was low, the temperature difference of TEG was small, thus the electrical efficiency of TEG was close to the zero (Figure 10.25). However, when the solar radiation was high, the electrical efficiency of TEG presented a trend of rapid growth. On the other hand, with the hot side temperature increase, which means when the PV temperature increased, the PV electrical efficiency had a decrease tendency.

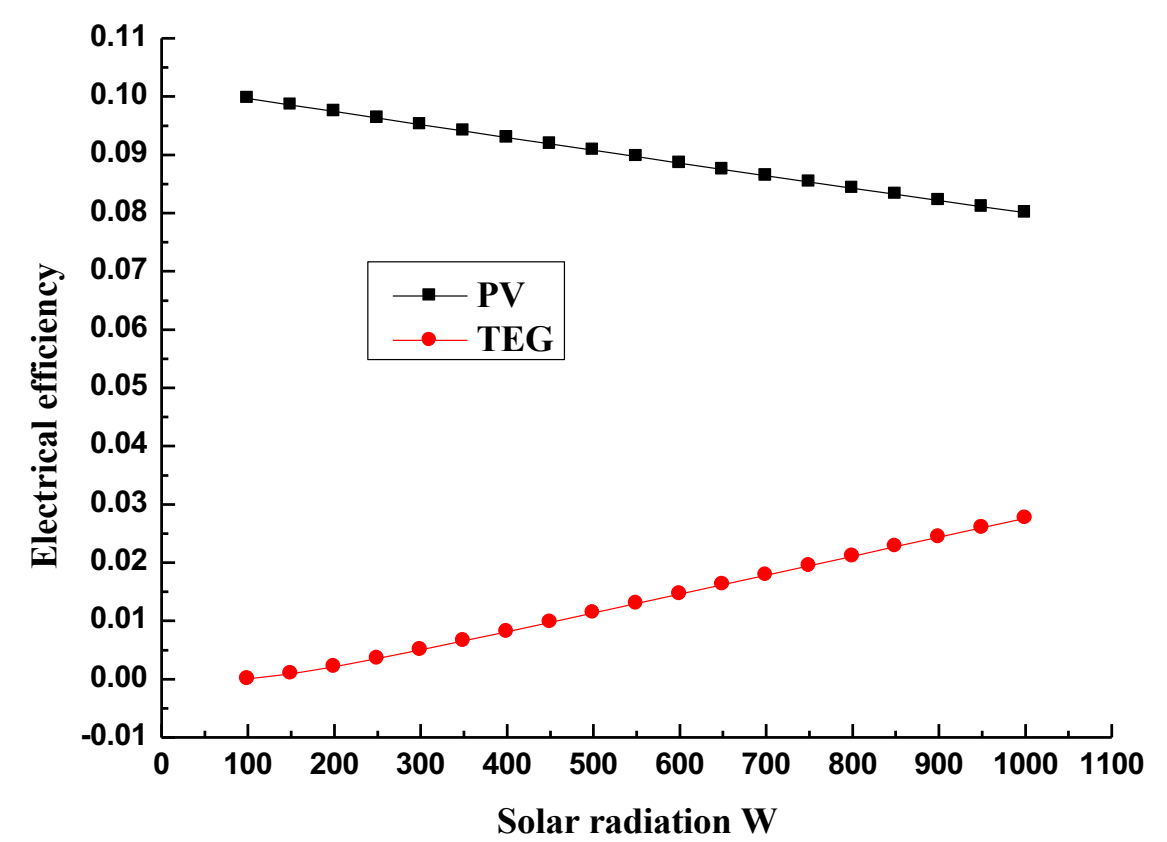

Figure 10.25 Electrical efficiency of PV and TEG in PV-TE system at different solar 


\section{radiation}

When the radiation was low, the electrical efficiency of TEG was small, so the system efficiency of TEG became lower. However, when the radiation was high, the electrical efficiency of TEG was larger, so the system efficiency of TEG became higher.

Therefore, with the solar radiation increased, the system efficiency of PV-TE presented the fall and then rise tendency (Figure 10.26). For the conventional PV system, with the solar radiation increase, the PV temperature became higher, so the system efficiency presented a decrease tendency.

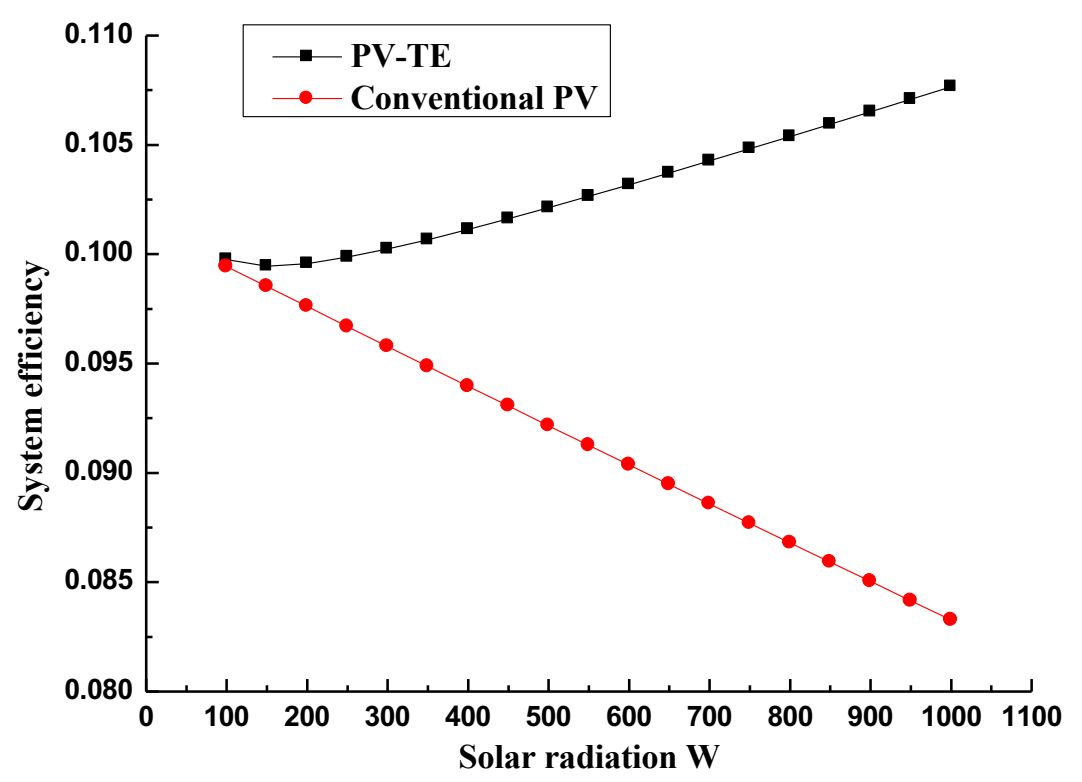

Figure 10.26 System efficiency comparison between PV-TE and conventional PV at

\section{different solar radiation}

\section{b) Different wind speeds}

Increase in the wind speed will enhance the cooling of the heat sink, which would be beneficial to the TEG. Nevertheless, the larger wind speed would also increase the thermal losses on the PV via the heat convection to the environment, which will decrease the hot side temperature of TEG and affect the TEG electrical efficiency negatively. Therefore, the comprehensive performance is needed to evaluate the specific working condition. Figure 10.27 showed the 
variation curves of the hot and cold side temperature of TEG at different wind speeds when the solar radiation was $1000 \mathrm{~W}$ and the ambient temperature was $298 \mathrm{~K}$. It is clear that with the wind speed increase, the temperature difference of TEG became larger and then smaller. That also indicated that the TEG output would be higher and then lower.

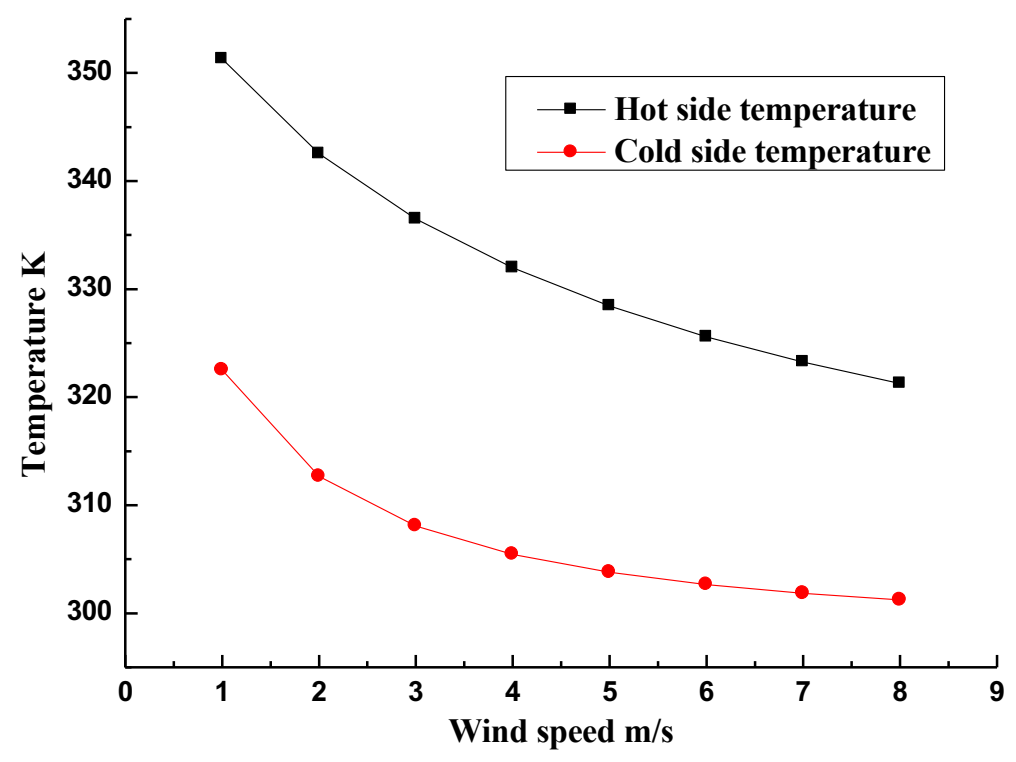

Figure 10.27 TEG hot and cold side temperature at different wind speeds

With the different wind speeds, the electrical efficiency of PV and TEG are shown in Figure 10.28. The curve of the TEG electrical efficiency was in keeping with that of the temperature difference, which indicated a rise then fall tendency. For the PV efficiency, the curve presented a rising trend, but the rising amplitude became smaller, which means that when the wind speed increased to a high value, the PV electrical efficiency would be affected in a small range. 


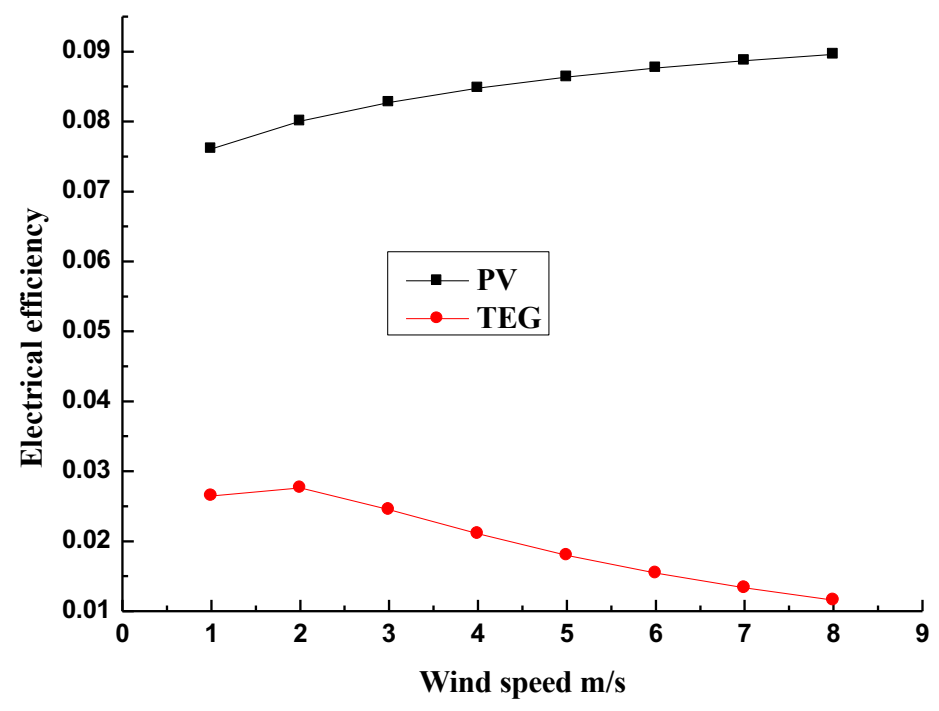

Figure 10.28 Electrical efficiency of PV and TEG in PV-TE system at different wind speed

The comparison between the PV-TE and conventional PV in terms of system efficiency is shown in Figure 10.29. With the increase of the wind speed, the PV-TE system efficiency presented a rising then fall tendency. In the range of the low wind speeds, the PV output increase was larger than the TEG output decrease. But in the range of the high wind speed, the PV output increase was lower than the TEG output decrease, so the system efficiency decreased significantly.

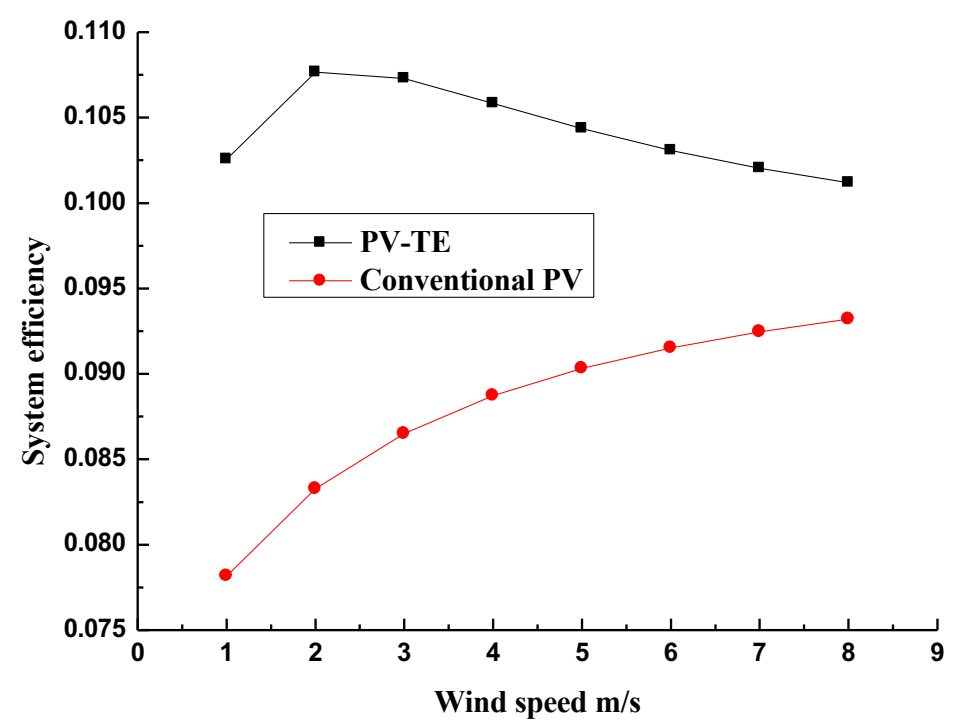

Figure 10.29 System efficiency comparison between PV-TE and conventional PV at 


\section{different wind speeds}

\section{c) Different ambient temperature}

When the solar radiation was $1000 \mathrm{~W}$ and the wind speed was $2 \mathrm{~m} / \mathrm{s}$, the hot and cold side temperature of TEG were all raised with the ambient temperature increase (Figure 10.30). The temperature difference slightly became smaller when the ambient temperature became higher.

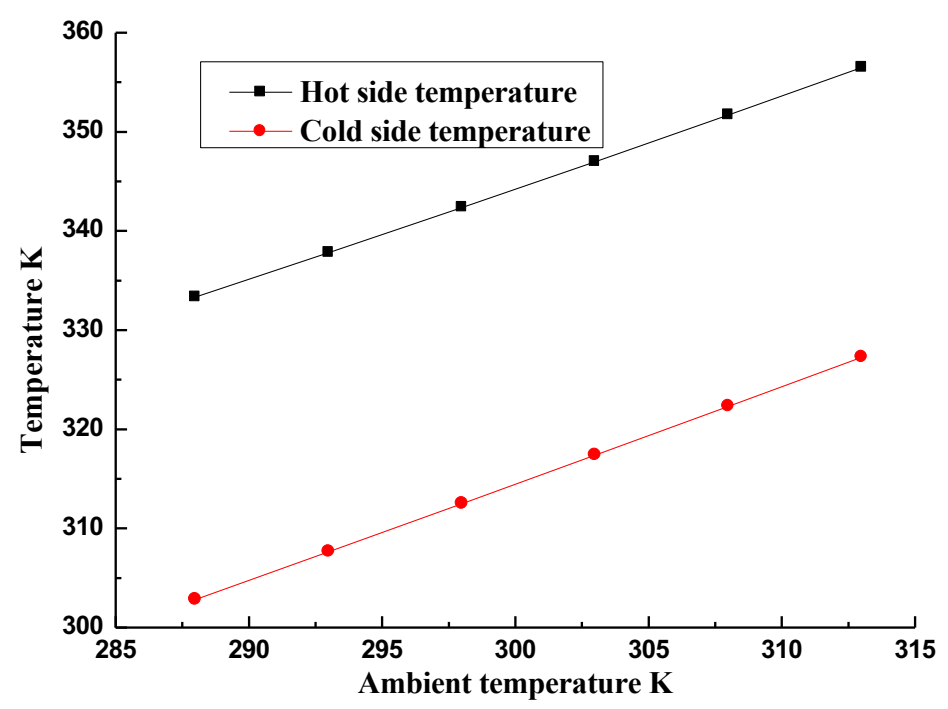

Figure 10.30 TEG hot and cold side temperature at different ambient temperature

In the PV-TE system, the TEG electrical efficiency changed in a small scope since the variation of the temperature difference of TEG was small (Figure 10.31). But it is clear that the PV electrical efficiency had a significant decrease tendency, because the PV temperature rose with the ambient temperature increase. 


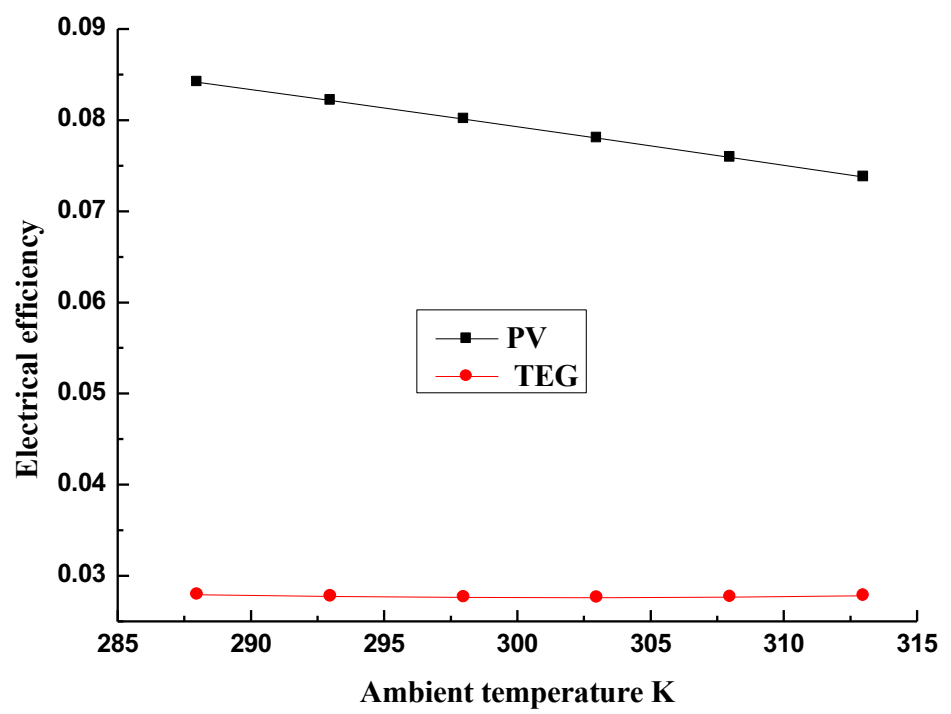

Figure 10.31 Electrical efficiency of PV and TEG in PV-TE system at different ambient temperature

The variation tendency of the PV-TE system and the conventional PV system were all downward with the increase of the ambient temperature, which was due to the higher temperature leading to the lower PV efficiency. However, because of the TEG output, the new PV-TE system was still higher than the conventional PV system.

\section{C) Annual output and preliminary economic analysis}

To predict the annual performance of the new PV-TE system, a numerical simulation program written using MATLAB has been developed. The Efficiency comparison of PV, novel PV-TE and conventional PV-TE with different solar radiations was shown in Figure 10.32. The electrical efficiency of the conventional PV-TE is the highest one, and that of the PV is lowest one.

In the present simulation, the PV-TE system would collect the solar energy. The weather data were provided by EnergyPlus. The weather data in half an hour is the average value, so the weather data changes every half an hour. 


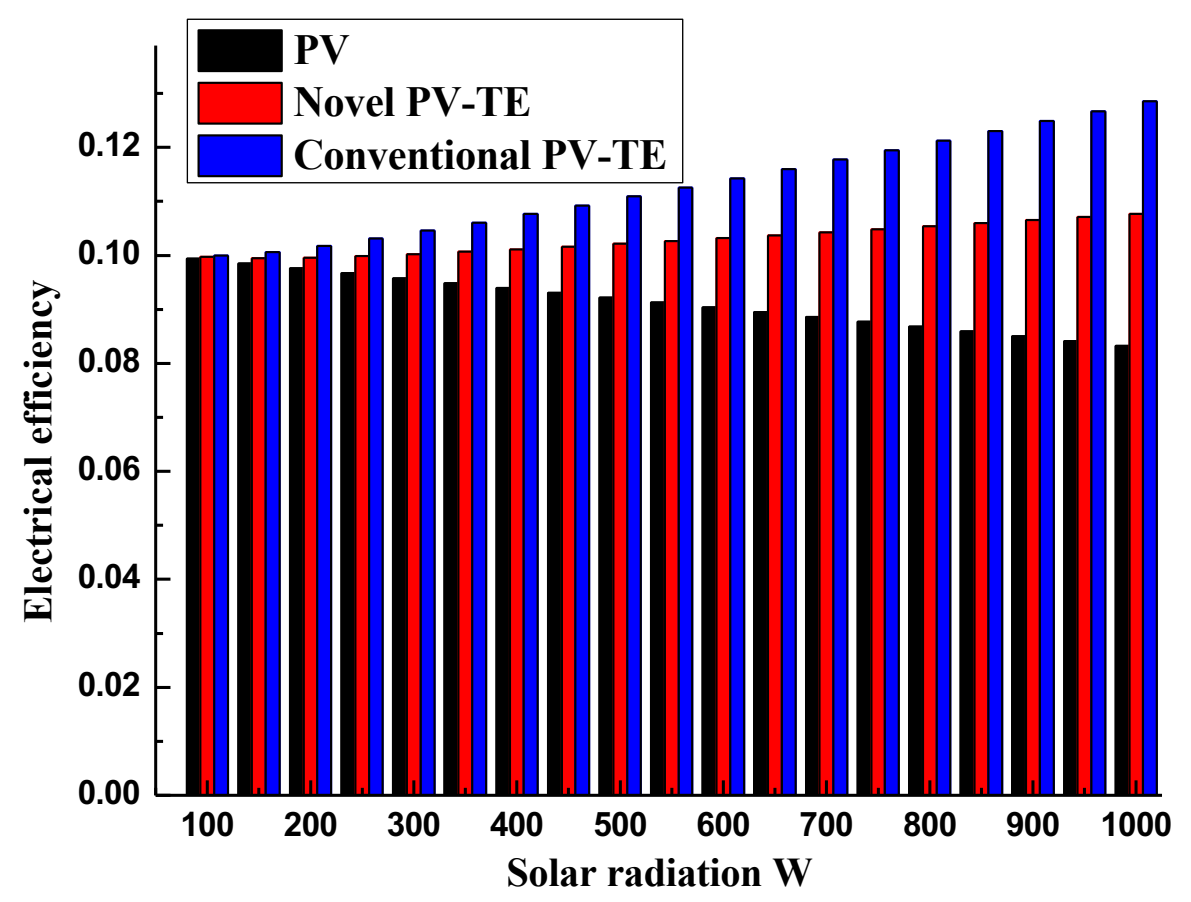

Figure 10.32 Efficiency comparison of PV, novel PV-TE and conventional PV-TE

For the conventional PV-TE system, its economic advantage over the conventional PV system is existent. So, the key issue in this study is that whether the proposed new PV-TE has advantages in terms of efficiency and cost over the common PV system. The annual electricity outputs of the novel PV-TE system, the conventional PV-TE system and the PV system are shown in Figure 10.33.

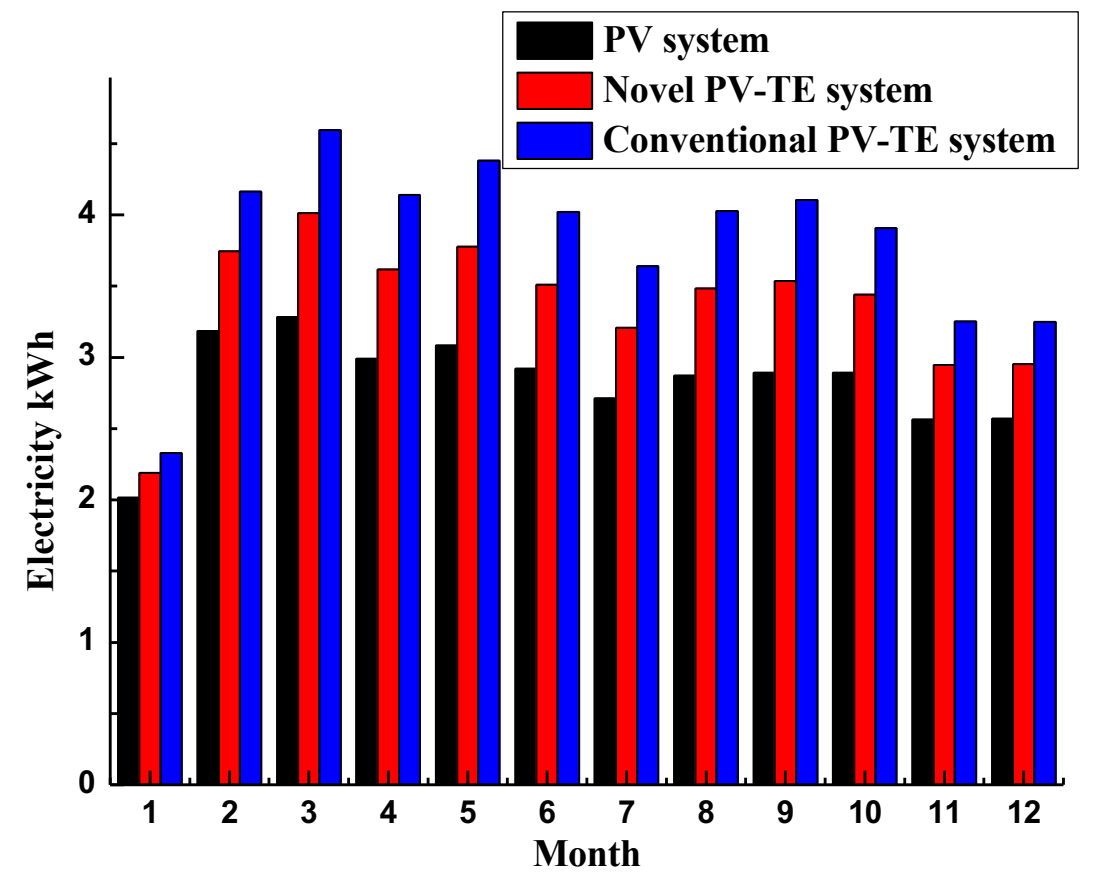




\section{Figure 10.33 Electricity production comparison of PV, novel PV-TE and conventional PV-TE systems in Hefei}

In winter, the electricity difference between the new PV-TE system and conventional PV system was lower than that in summer, which may be because the low ambient temperature was beneficial to the conventional PV system. From Figure 10.33, it can be seen that the new PV-TE system can attain more about $6.44 \mathrm{kWh}$ annual electricity output than the conventional PV system with the same area in Hefei $\left(31^{\circ} 53^{\prime} \mathrm{N}, 117^{\circ} 15^{\prime}\right.$ E)in the eastern region of China. And the conventional PV-TE system can attain more about $5.40 \mathrm{kWh}$ annual electricity output than the novel PV-TE system.

From the perspective of the investment and return, the efficiency is just a factor, and the economic factors such as the ratio of output to input are also important. However, for the conventional PV-TE, due to the pair-arrangement between the PV and TE module, the extra costs is high with the same area, which can be approximately calculated ( $¥ 22 * 1.2 * 0.18 / 0.055^{2}$ $=¥ 1570$ ), which is about 41 times higher than the extra costs of the new PV-TE. At the same time, the extra annually electrical production of the conventional PV-TE is just 2 times higher $((6.44+5.40) / 6.44 \approx 2)$ than that of the new PV-TE. Therefore, the new PV-TE has the economic advantage over the conventional PV-TE. 


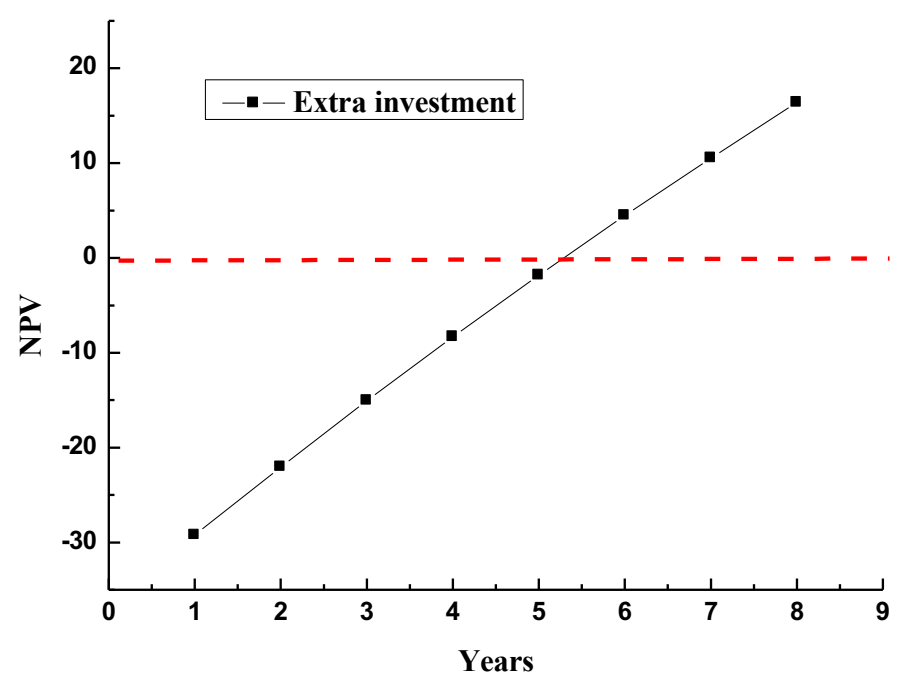

Figure 10.34 Pay-Back-Period of the novel PV-TE system

Consequently, in this section, the comparison between the new PV-TE system and the conventional PV system will be presented. The present section regards the economic analysis of the system, where the parameter concerning the electricity cost will be $¥ 1.20 / \mathrm{kWh}$. The basic methodology is deployed for the calculation of the economic performance.

The coefficient that correlates a future cash flow with a present value is called the present value coefficient and is given by the following Eq. (10.4).

$C F_{t=0}=\frac{C F_{t=0}}{(1+r)^{n}}$

Where $r$ is the interest rate.

The net present value (NPV), which is actually the present value of the total cash flow during the economic lifecycle of a system, is given by Eq. (10.5).

$N P V=\sum_{j=1}^{n} \frac{B_{t=j}-C_{t=j}}{(1+r)^{j}}$

Where $B$ is the present value of the benefit; $C$ is the present value of the cost; $j$ is the time period.

The Pay-Back-Period (PBP) is the time-period in years required for the NPV to reach a zero value and is found by solving Eq. (10.5) with NPV $=0$. The higher NPV means the more profit 
during the life cycle. In this section, due to the two systems having the same area of PV, only the PBP of the extra investment needs to be calculated. Here, it is assumed that the labor and maintenance costs of the new PV-TE system are the same as that of the conventional PV system. Thus, the recovery cost of the extra investment will be achieved in six years (Figure 10.34), which means from the sixth year, the new PV-TE system has a higher ratio of output to input than the conventional PV system. Therefore, the new PV-TE system constitutes from the techno-economic aspect a more efficient solution for the power production.

\subsection{Conclusion}

Solar energy is one of the renewable energy resources with large potential. Combining the solar energy with TE will attain the electrical output, at the same time it can also provide the thermal output. The TE device can be integrated with solar thermal system, solar hot water system and PV system etc. It can be foreseen that the TE can fully use the remnant heat from solar energy. In addition, since the low efficiency and high price of TE, the optimization system needs to reduce the quantity of TE device to enhance the cost performance.

\section{References}

[10.1] W. He, G. Zhang, X. Zhang, J. Jie, G. Li, X. Zhao. Recent development and application of thermoelectric generator and cooler. Applied Energy, 2015, 143:1-25

[10.2] G. Li, J. Ji, G. Zhang, W. He, X. Chen, H. Chen. Performance analysis on a novel microchannel heat pipe evacuated tube solar collector-incorporated thermoelectric generation. International Journal of Energy Research, 2016, 40(15): 2117- 2127 
[10.3] G. Li, W. Feng, Y. Jin, X. Chen, J. Ji. Discussion on the solar concentrating thermoelectric generation using micro-channel heat pipe array. Heat and Mass Transfer, 2017, 53(11):3249-3256

[10.4] G. Li, G. Zhang, W. He, J. Ji, S. Lv, X. Chen, H. Chen. Performance analysis on a solar concentrating thermoelectric generator using the micro-channel heat pipe array. Energy Conversion and Management, 2016, 112:191-198

[10.5] G. Li, X. Zhao, J. Ji. Conceptual development of a novel photovoltaic-thermoelectric system and preliminary economic analysis. Energy Conversion and Management, 2016, 126: $935-943$ 